University of Nebraska - Lincoln

DigitalCommons@University of Nebraska - Lincoln

\title{
Radiometer Footprint Model to Estimate Sunlit and Shaded Components for Row Crops
}

\author{
Paul D. Colaizzi \\ USDA-ARS, Paul.Colaizzi@ARS.USDA.GOV \\ S. A. O'Shaughnessy \\ USDA-ARS, Susan.OShaughnessy@ars.usda.gov \\ Prasanna H. Gowda \\ USDA-ARS, prasanna.gowda@ars.usda.gov \\ Steven R. Evett \\ USDA-ARS, steve.evett@ars.usda.gov \\ T. A. Howell \\ USDA-ARS, Terry.Howell@ars.usda.gov
}

See next page for additional authors

Follow this and additional works at: https://digitalcommons.unl.edu/usdaarsfacpub

Colaizzi, Paul D.; O'Shaughnessy, S. A.; Gowda, Prasanna H.; Evett, Steven R.; Howell, T. A.; Kustas, William P.; and Anderson, M. C., "Radiometer Footprint Model to Estimate Sunlit and Shaded Components for Row Crops" (2010). Publications from USDA-ARS / UNL Faculty. 1826.

https://digitalcommons.unl.edu/usdaarsfacpub/1826

This Article is brought to you for free and open access by the U.S. Department of Agriculture: Agricultural Research Service, Lincoln, Nebraska at DigitalCommons@University of Nebraska - Lincoln. It has been accepted for inclusion in Publications from USDA-ARS / UNL Faculty by an authorized administrator of DigitalCommons@University of Nebraska - Lincoln. 


\section{Authors}

Paul D. Colaizzi, S. A. O'Shaughnessy, Prasanna H. Gowda, Steven R. Evett, T. A. Howell, William P. Kustas, and M. C. Anderson 


\title{
Radiometer Footprint Model to Estimate Sunlit and Shaded Components for Row Crops
}

\author{
P. D. Colaizzi,* S. A. O’Shaughnessy, P. H. Gowda, S. R. Evett, T. A. Howell, \\ W. P. Kustas, and M. C. Anderson
}

\begin{abstract}
This article describes a geometric model for computing the relative proportion of sunlit vegetation, shaded vegetation, sunlit soil, and shaded soil appearing in a circular or elliptical radiometer footprint for row crops, where the crop rows were modeled as continuous ellipses. The model was validated using digital photographs of row crops, where each component was determined by supervised classification. Root mean squared errors (RMSE) between modeled and observed components were 35, 49, 29, and 44\% of observed means for sunlit vegetation, shaded vegetation, sunlit soil, and shaded soil, respectively. Mean bias errors (MBE) were, respectively, -5.6, 16.6, -4.0, and $-0.5 \%$ of observed means. The continuous ellipse model was compared to the commonly used clumping index model, where the latter estimates total vegetation and total soil, but does not resolve these into their sunlit or shaded components and does not account for radiometer footprint shape dimensions. The continuous ellipse model resulted in RMSE for vegetation and soil of 22 and $19 \%$, respectively, whereas the clumping index model resulted in respective RMSE of 37 and $31 \%$. The continuous ellipse model had MBE of 3.3 and $-2.6 \%$ for vegetation and soil, respectively, which was slightly greater than the respective MBE of -1.5 and $1.4 \%$ for clumping index model. Given the model sensitivity and uncertainty of leaf area index (LAI), the RMSE and MBE resulting from the continuous ellipse model would not be expected to be less than $20 \%$ of the observed means, and model performance was therefore deemed reasonable in this study.
\end{abstract}

$\mathrm{R}$ EMOTE SENSING, WHERE the reflectance and temperature of vegetated surfaces are sensed by non-contact radiometers, has long been viewed as a more efficient approach to estimate crop conditions compared with in situ sensors (Jackson, 1984). Present satellite and aircraft remote sensing platforms generally lack the spatial and temporal resolutions required for irrigation and crop management at the farm scale, which are on the order of a few meters and a few days, respectively (Jackson, 1984). In addition, measurements from satellites and aircraft require extensive processing (e.g., atmospheric and geometric correction), which has entailed greater turnaround times (i.e., time from field measurement to useful data product) compared with what might be possible using ground-based sensors (Moran, 1994). Therefore, ground-based remote sensing appears to be most feasible for farm scale applications. Farm machinery, which passes over the field at regular intervals, can provide a convenient remote sensing platform. Self-propelled center pivot and lateralmove irrigation systems, which are replacing gravity irrigation in many intensively irrigated regions such as the U.S. Great Plains

P.D. Colaizzi, S.A. O'Shaughnessy, P.H. Gowda, S. R. Evett and T.A. Howell, USDA-Agricultural Research Service, Conservation and Production Research Laboratory, P.O. Drawer 10, Bushland, TX 79012-0010; W.P. Kustas and M.C. Anderson, USDA-Agricultural Research Service, Hydrology and Remote Sensing Research Laboratory, Building 007, BARC-West, Beltsville MD 20705-2350. Received 5 Oct. 2009. ${ }^{*}$ Corresponding author (paul.colaizzi@ars.usda.gov).

Published in Agron. J. 102:942-955 (2010)

Published online 24 Mar. 2010

doi:10.2134/agronj2009.0393

Copyright (C) 2010 by the American Society of Agronomy, 5585 Guilford Road, Madison, WI 53711. All rights reserved. No part of this periodical may be reproduced or transmitted in any form or by any means, electronic or mechanical, including photocopying, recording, or any information storage and retrieval system, without permission in writing from the publisher.
(Colaizzi et al., 2009), have been used to transport reflectance sensors and infrared thermometers. These data have been used to derive spatially distributed maps of vegetation vigor, evapotranspiration (ET), crop water stress, and N status at suitable spatial and temporal resolutions, which is important for management of irrigation, fertilizer, and other crop inputs (Sadler et al., 2002; Colaizzi et al. (2003a), 2003b; Kostrzewski et al., 2003; ElShikha et al. (2007, 2008); Peters and Evett, 2007, 2008).

Agricultural applications of remote sensing typically involve partial vegetation cover, such as row crops or orchards, which are examples of nonrandomly distributed vegetation (Campbell and Norman, 1998). Partial vegetation cover may consist of up to four components (sunlit and shaded soil, sunlit and shaded vegetation) appearing within a radiometer field of view (Fitzgerald et al., 2005). In sunlit conditions, each component may have substantially different radiometric surface temperatures. For example, sunlit and shaded soil temperatures may differ by as much as $30^{\circ} \mathrm{C}$, which must be accounted for in two-layer (soil and vegetation) surface

Abbreviations: $E_{\mathrm{C}}$, modified coefficient of model efficiency (no units); ET, evapotranspiration; $f$, digital camera focal length $(\mathrm{mm})$; FOV, radiometer field-of-view number (no units); $f_{\text {SOIL }}$, area fraction of total soil appearing to a radiometer (no units); $f_{\mathrm{VEG}}$, area fraction of total vegetation appearing to a radiometer (no units); $h_{\mathrm{C}}$, canopy height $(\mathrm{m}) ; H_{\mathrm{DET}}$, height of the digital camera detector $(\mathrm{mm})$; LAI, leaf area index $\left(\mathrm{m}^{2} \mathrm{~m}^{-2}\right)$; MAE, mean absolute error (same units as modeled and observed parameter); MBE, mean bias error (same units as modeled and observed parameter); $r$, crop row spacing (m); RMSE, root mean squared error (same units as modeled and observed parameter); $S_{\mathrm{P}}$, sensitivity of a modeled component to an input parameter (no units); $w_{\mathrm{C}}$, canopy width (m); $Z_{-}$, value of a modeled component resulting when an input parameter is decreased a percentage of its base value (units vary); $Z_{+}$, value of a modeled component resulting when an input parameter is increased a percentage of its base value (units vary); $Z_{0}$, value of a modeled component resulting when an input parameter equals its base value (units vary); $\theta_{\mathrm{R}}$, radiometer zenith view angle ( $\mathrm{rad}) ; \theta_{S}$, solar zenith view angle $(\mathrm{rad}) ; \Phi_{\mathrm{R}}$, radiometer azimuth angle relative to a crop row (rad); $\Phi_{S}$, solar azimuth angle relative to a crop row $(\mathrm{rad}) \Omega$, clumping index (no units); $\zeta_{\mathrm{V}}$, vertical number of pixels of the extraction shape used to simulate a circular or elliptical radiometer footprint in a digital image; $\zeta_{\mathrm{V}, \mathrm{MAX}}$, total vertical number of pixels contained in a digital image. 
energy balance models (Kustas and Norman, 1999). Although narrow field-of-view radiometers at large zenith angles may allow the number of viewed components to be reduced, Peters and Evett (2008) reported that narrow (5:1) field-of-view infrared thermometers were more sensitive to changes in ambient air temperatures compared with a wider (2:1) field-of-view. Much of their study was therefore limited to a larger canopy size where no soil was directly visible at a $45^{\circ}$ zenith view angle using a relatively wide $28^{\circ}(2: 1)$ field-of-view infrared thermometer. Nonetheless, many critical farm management decisions occur early in the season when the canopy size is relatively small and viewing all components is unavoidable. Also, regardless of canopy size, canopy biophysical characteristics useful for fertilizer and pest management and radiative transfer models can be determined by the distribution of sunlit and shaded leaves (Campbell and Norman, 1998; Fitzgerald et al., 2005). Hence, some means of accounting for the relative proportions of components appearing to a radiometer is required for remote sensing to have wider applications in crop management.

The spatial distribution of vegetation has generally been described as random, dispersed, or clumped, and the clumped category usually applies to row crops and forests. To account for the relative proportion of vegetation and soil appearing to a radiometer for clumped vegetation, several studies have used the semi-empirical clumping index approach (e.g., Nilson, 1971; Chen and Cihlar, 1995; Campbell and Norman, 1998; Anderson et al., 2005). The clumping index has been applied to radiative transfer models to account for greater radiation interception of clumped vegetation compared with randomly distributed vegetation (Campbell and Norman, 1998), and has been applied to row crops in two-layer surface energy balance models (Kustas and Norman, 1999; Anderson et al., 2005). The clumping index approach appears robust for a wide range of vegetation types; however, it is generally limited to applications that do not require partitioning soil and vegetation further into their sunlit and shaded components, and does not consider the radiometer field-of-view. Inclusion of sunlit and shaded components, and/or radiometer field-of-view, generally requires three-dimensional models of the canopy structure.

The three-dimensional structure of crop canopies has been modeled using simple geometric shapes such as ellipsoids (Mann et al., 1980; Norman and Welles, 1983), cubes (Arkin et al., 1978), or continuous rectangles (Allen, 1974; Jackson et al., 1979; Kimes, 1983; Gijzen and Goudriaan, 1989). Jackson et al. (1979) developed an algorithm to retrieve the sunlit and shaded soil and vegetation components using the multiple view angles of radiometers that scan the surface in a wisk-broom motion. Kimes (1983) modified this algorithm to retrieve component temperatures and canopy heights and widths of a cotton row crop measured with a ground-based infrared thermometer. Radiometers generally have circular or elliptical footprints resulting from a cone cross-section for nadir and off-nadir view angles, respectively, and the footprint dimensions depend on the sensor height, field-of-view angle, and zenith view angle (Bugbee et al., 1998; Baker et al., 2001). These parameters were not included in the Kimes (1983) algorithm; instead, the proportions of sunlit and shaded soil and vegetation were computed based on assuming a square pixel, which is straight-forward when crop rows are modeled as continuous rectangles. However, if the footprint size is similar to the crop row spacing, the proportion of each component may be substantially different depending on the footprint shape. For example, consider square and circular footprints having the same side dimension or diameter, respectively, as a crop row spacing, with the footprints centered on the crop canopy (i.e., a nadir-viewing radiometer directly above the canopy). A canopy width that is $50 \%$ of the row spacing (i.e., $50 \%$ canopy cover) will result in the square footprint containing 50\% canopy, but the circular footprint containing 69\% canopy. Assuming the soil temperature is greater than the canopy, the composite surface temperature would be greater for the square footprint compared with the circular footprint. The circular or elliptical footprint shape of ground-based radiometers should therefore be accounted for when estimating the proportions of components.

In this study, we propose a relatively simple geometric model for estimating the area fraction of sunlit and shaded soil and vegetation appearing in a circular or elliptical footprint of a radiometer that views a row crop. The crop canopies were modeled as continuous ellipses, which greatly simplified calculations compared with other geometric shapes used in previous models, but was nonetheless deemed a reasonable approximation of a real canopy. The model was tested using digital photographs of corn (Zea mays L.), cotton (Gossypium hirsutum L.), cowpea [Vigna unguiculata (L.) Walp.], and sorghum [Sorghum bicolor (L.) Moench.] canopies. The model was also compared with the clumping index approach in predicting the total (sunlit + shaded) soil and vegetation components. The model is intended to improve the robustness of remote sensing algorithms designed for ground-based radiometers viewing row crops, such as those aboard self-propelled irrigation systems.

\section{MODEL DESCRIPTION Continuous Ellipse Model}

The geometric model proposed herein is described by considering a radiometer that views a row crop at zenith view angle $\theta_{R}$ and azimuth angle $\Phi_{\mathrm{R}}$ relative to the crop rows (Fig. 1). The radiometer was assumed to have a circular or elliptical footprint at nadir and off-nadir views, respectively. The crop canopy rows were modeled as continuous ellipses, where the cross-section of only a single canopy row was shown to simplify Fig. 1 . The cross-section of a continuous ellipse has vertical and horizontal semiaxes $a_{\mathrm{C}}$ and $b_{\mathrm{C}}$, respectively $(\mathrm{m})$. The radiometer footprint (projected below the canopy in Fig. 1) contains the canopy, sunlit soil, and shaded soil components. If the canopy was solid and impenetrable to sunlight, the total area of canopy appearing in the radiometer footprint would be the area that is bound by the chords that are $\mathrm{H}_{1}$ and $\mathrm{H}_{2}$ from $\mathrm{B}$. The area fraction of a solid canopy appearing in the radiometer footprint $\left(f_{\mathrm{C}^{\prime}}\right)$ is

$$
f_{\mathrm{C}}^{\prime}=\frac{\left(A_{\mathrm{H} 2}-A_{\mathrm{H} 1}\right)}{A_{\mathrm{R}}}
$$

and those of sunlit $\left(f_{\text {SOIL,SUN }}{ }^{\prime}\right)$ and shaded $\left(f_{\text {SOIL,SHD }}{ }^{\prime}\right)$ soils are

$$
\begin{aligned}
& f_{\text {SOIL,SUN }}{ }^{\prime}=\frac{\left[A_{\mathrm{R}}-\max \left(A_{\mathrm{H} 2}, A_{\mathrm{H} 4}\right)+\min \left(A_{\mathrm{H} 1}, A_{\mathrm{H} 3}\right)\right]}{A_{\mathrm{R}}} \\
& f_{\text {SOIL,SHD }}{ }^{\prime}=\frac{\left[\max \left(0, A_{\mathrm{H} 1}-A_{\mathrm{H} 3}\right)+\max \left(0, A_{\mathrm{H} 4}-A_{\mathrm{H} 2}\right)\right]}{A_{\mathrm{R}}}
\end{aligned}
$$

where $A_{\mathrm{R}}$ is the area of the radiometer footprint, and $A_{\mathrm{H} 1}, A_{\mathrm{H} 2}$, $A_{\mathrm{H} 3}$, and $A_{\mathrm{H} 4}$ are the areas within the radiometer footprint bound by chords that are $\mathrm{H}_{1}, \mathrm{H}_{2}, \mathrm{H}_{3}$, and $\mathrm{H}_{4}$ from $\mathrm{B}$, respectively. 
The minimum and maximum functions in Eq. [2] and [3] account for the fact that some boundaries in the radiometer footprint will be obscured by the canopy $\left(\mathrm{H}_{4}\right.$ in this case), which depends on the radiometer view angle relative to the sun. Procedures for computing the areas in Eq. [1], [2], and [3] are given in Appendix 1.

Since real canopies are not impenetrable to sunlight, canopies will contain both sunlit and shaded leaves, shaded soil may contain sun flecks (due to direct beam radiation transmitted through the canopy), and both sunlit and shaded soil may be visible beneath the canopy. Although sun flecks on shaded soil are likely to be ephemeral and hence not likely to have a surface temperature much greater than the surrounding shaded soil, sun flecks are a significant portion of the sunlit soil component and should be accounted for in biophysical modeling applications (Fitzgerald et al., 2005). Therefore, light penetration through the canopy was accounted for using a transmittance coefficient for direct beam radiation, and expressions for each component were derived based on equations of Campbell and Norman (1998) as follows:

$$
f_{\mathrm{VEG}, \mathrm{SUN}}=f_{\mathrm{C}}^{\prime}\left[1-\tau_{\mathrm{b}}\left(\theta_{\mathrm{R}}\right)\right]\left[1-\tau_{\mathrm{b}}\left(\theta_{\mathrm{S}}\right)\right]
$$

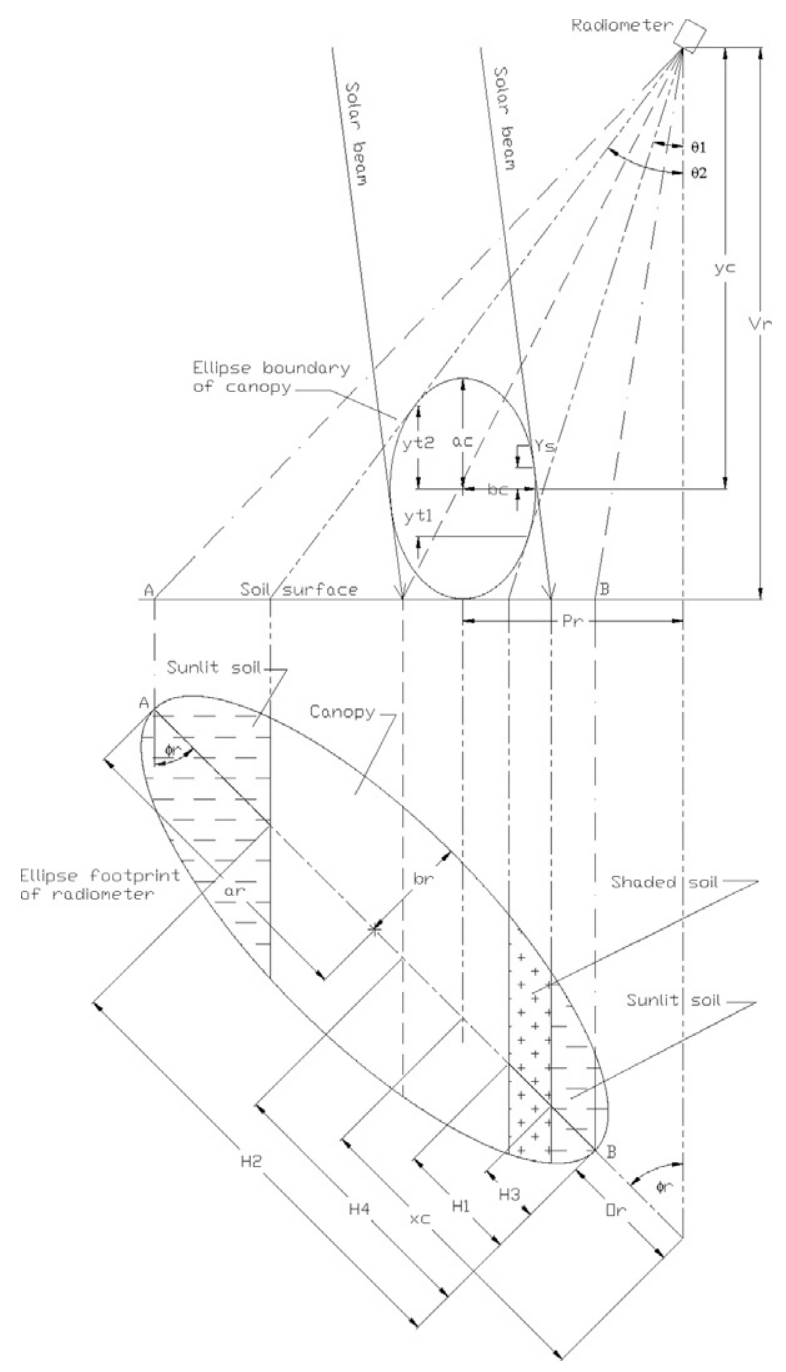

Fig. I. Radiometer footprint viewing a single canopy row modeled as a continuous ellipse, and chord locations used to compute areas of sunlit soil, shaded soil, and canopy appearing in the radiometer footprint.

$$
\begin{aligned}
& f_{\mathrm{VEG}, S H D}=f_{\mathrm{C}}^{\prime}\left[1-\tau_{\mathrm{b}}\left(\theta_{\mathrm{R}}\right)\right]-f_{\mathrm{VEG}, S \mathrm{SUN}} \\
& f_{\text {SOIL,SUN }}=f_{\text {SOIL,SUN }}{ }^{\prime}+f_{\mathrm{C}}^{\prime} \tau_{\mathrm{b}}\left(\theta_{\mathrm{R}}\right) \tau_{\mathrm{b}}\left(\theta_{\mathrm{S}}\right)+f_{\text {SOIL,SHD }}^{\prime} \tau_{\mathrm{b}}\left(\theta_{\mathrm{S}}\right) \\
& f_{\text {SOIL,SHD }}=f_{\text {SOIL,SHD }}{ }^{\prime}\left[1-\tau_{\mathrm{b}}\left(\theta_{\mathrm{S}}\right)\right]+{f_{\mathrm{C}}^{\prime}}^{\prime} \tau_{\mathrm{b}}\left(\theta_{\mathrm{R}}\right)\left[1-\tau_{\mathrm{b}}\left(\theta_{\mathrm{S}}\right)\right]
\end{aligned}
$$

where $f_{\mathrm{VEG}, \mathrm{SUN}}$ is the area fraction of sunlit vegetation, $f_{\mathrm{VEG}, \mathrm{SHD}}$ is the area fraction of shaded vegetation, $f_{\text {SOIL,SUN }}$ is the area fraction of sunlit soil, $f_{\text {SOIL,SHD }}$ is the area fraction of shaded soil, $\tau_{b}\left(\theta_{R}\right)$ is the transmittance of shortwave or longwave radiation for a radiometer viewing the canopy at zenith angle $\theta_{R}$, and $\tau_{b}\left(\theta_{S}\right)$ is the transmittance of beam solar radiation for solar zenith angle $\theta_{S}$. In Eq. [6], the second term represents sunlit soil that is visible beneath the canopy, and the third term represents sun flecks in shaded soil from beam radiation being transmitted through the canopy. In Eq. [7], the first term accounts for sun flecks in shaded soil, and the second term represents shaded soil that is visible beneath the canopy. Transmittance of radiation at zenith angle $\theta$ was computed based on simple exponential extinction as:

$$
\tau_{\mathrm{b}}(\theta)=\exp \left[-\kappa_{\mathrm{b}}(\theta) \times P_{\mathrm{L}}(\theta) \times M_{\mathrm{R}}(\theta) \times \mathrm{LAI} \times r / w_{\mathrm{c}}\right]
$$

where $\kappa_{b}$ is the extinction coefficient for direct beam radiation, $P_{\mathrm{L}}$ is the path length fraction of a radiation path through a canopy relative to nadir, and $M_{\mathrm{R}}$ is the multiple row factor that accounts for a radiation path traversing across more than one canopy row (i.e., at greater zenith angles), LAI is leaf area index $\left(\mathrm{m}^{2} \mathrm{~m}^{-2}\right), r$ is the row spacing $(\mathrm{m})$, and $w_{\mathrm{C}}$ is the canopy width (m). $P_{\mathrm{L}}$ and $M_{\mathrm{R}}$ were new parameters derived for the continuous ellipse model, and computation procedures are given in Appendix 2. The factor $r / w_{C}$ is a consequence of nonrandomly distributed vegetation of row crops, in that LAI will be greater within the canopy compared with the overall field LAI. For visible direct beam radiation, $\kappa_{b}$ was computed using the ellipsoidal leaf angle distribution model (Campbell and Norman, 1998).

\section{Clumping Index Model}

Model agreement in terms of the total vegetation and soil components (i.e., sunlit + shaded), as predicted by the continuous ellipse geometric model, was compared to the clumping index approach to assess the justification for the somewhat greater complexity of the former. In the clumping index approach, the fraction of total vegetation appearing to a radiometer $\left(f_{\mathrm{VEG}}\right)$ was computed as:

$$
f_{\mathrm{VEG}}=1-\exp \left(\frac{-\kappa_{\mathrm{b}}\left(\theta_{\mathrm{R}}\right) \Omega\left(\theta_{\mathrm{R}}, \varphi_{\mathrm{R}}\right) \mathrm{LAI}}{\cos \theta_{\mathrm{R}}}\right)
$$

where $\Omega$ is defined as the clumping index, and Eq. [9] is the result of combining Eq. [4], [5], and [8] where the quantity $P_{\mathrm{L}} \times M_{\mathrm{R}} \times$ $r / w_{\mathrm{C}}$ in Eq. [8] was replaced by $\Omega / \cos \theta_{\mathrm{R}}$. For homogenous canopies with randomly distributed vegetation, $\Omega=1$, but clumped canopies such as row crops would result in $\Omega<1$. Procedures for computing $\Omega$ for row crops are given in Anderson et al. (2005).

\section{MATERIALS AND METHODS}

\section{Field Measurements}

Model validation in this study was based on digital photography of row crops. All data was obtained at the USDA-ARS 
Table I. Crops and input parameters used for model evaluation with digital photographs.

\begin{tabular}{|c|c|c|c|c|c|c|c|c|c|c|}
\hline Crop & Date & Time & $\mathbf{h}_{\mathbf{c}} \neq$ & $w_{c} \S$ & LAIT & Row & $\theta_{\mathbf{R}}^{\#}$ & $\Phi_{R}+\dagger$ & $\theta_{s}+t$ & $\Phi_{\mathbf{S}} \S \S$ \\
\hline & & CSTt & $\mathrm{m}$ & $\mathrm{m}$ & $m^{2} m^{-2}$ & orientation & 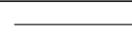 & $\bar{d}$ & rees & \\
\hline Corn & 8 June 2007 & 1542 & 0.58 & 0.25 & $0.4 I$ & $\mathrm{~S} 84^{\circ} \mathrm{E}$ & 65.6 & 0 & 39.9 & 12.1 \\
\hline Corn & 8 June 2007 & 1542 & 0.58 & 0.25 & 0.41 & $\mathrm{~S} 84^{\circ} \mathrm{E}$ & 78.2 & 90 & 39.9 & 12.1 \\
\hline Corn & 30 May 2009 & |343-|404 & 0.29 & 0.20 & 0.26 & $\mathrm{~S} 88^{\circ} \mathrm{E}$ & $0-60$ & $0-90$ & $18.3-2 \mid .7$ & $34.9-45.1$ \\
\hline Corn & 8 June 2009 & $|223-130|$ & 0.50 & 0.34 & 0.59 & $\mathrm{~S} 88^{\circ} \mathrm{E}$ & $0-60$ & $0-90$ & $12.7-13.4$ & $63.3-88.9$ \\
\hline Corn & I 5 June 2009 & $1233-1300$ & 0.68 & 0.55 & 1.12 & $\mathrm{~S} 88^{\circ} \mathrm{E}$ & $0-60$ & $0-90$ & $11.9-12.3$ & 71.0-98.4 \\
\hline Cotton & 26 July 2007 & 827 & 0.50 & 0.34 & 1.55 & SI72E & 67.2 & 0 & 60.4 & 78.3 \\
\hline Cotton & 26 July 2007 & 900 & 0.50 & 0.40 & 1.68 & S90E & 70.3 & 0 & 53.7 & 0.9 \\
\hline Cotton & I I Aug. 2007 & 953 & 0.55 & 0.37 & 0.96 & S84E & $63.3,66.3$ & 0,90 & 45.0 & 8.9 \\
\hline Cotton & 20 July 2008 & 829 & 0.40 & 0.20 & 0.60 & SOE & 38.3 & 0,90 & 59.5 & 85.5 \\
\hline Cotton & 20 July 2008 & 853 & 0.56 & 0.37 & 0.68 & S90E & 30.8 & 90 & 54.6 & 11.2 \\
\hline Cotton & 21 July 2008 & 1134 & 0.41 & 0.27 & 0.68 & S90E & 0.0 & 0 & 23.2 & 145.0 \\
\hline Cotton & 21 July 2008 & 617 & 0.50 & 0.30 & 0.68 & SOE & 0.0 & 0 & 85.8 & 201.8 \\
\hline Cotton & 28 July 2008 & 733 & 0.61 & 0.45 & 1.27 & SOE & 76.6 & 0,90 & 71.7 & 79.7 \\
\hline Cotton & 28 July 2008 & 734 & 0.46 & 0.25 & 1.00 & SOE & 75.1 & 0,90 & 71.5 & 79.9 \\
\hline Cotton & 28 July 2008 & 738 & 0.65 & 0.44 & 1.35 & S90E & $79.2,73.1$ & 0,90 & 70.7 & 19.6 \\
\hline Cotton & 31 July 2008 & 819 & 0.61 & 0.50 & 1.35 & S90E & 0.0 & 0 & 62.8 & 3.4 \\
\hline Cotton & 31 July 2008 & 801 & 0.56 & 0.37 & 1.77 & SOE & 0.0 & 0 & 66.4 & 84.2 \\
\hline Cotton & 5 Aug. 2008 & 658 & 0.56 & 0.37 & 2.60 & SOE & $68.6,70.2$ & 0 & 79.8 & 77.0 \\
\hline Cotton & 5 Aug. 2008 & 702 & 0.80 & 0.60 & 1.35 & S90E & $68.3-74.0$ & 0 & $73.8-79.0$ & $9.0-22.5$ \\
\hline Cowpea & 26 July 2007 & 824 & 0.31 & 0.38 & 0.50 & SI25E & 65.5 & 0,90 & 61.0 & 30.9 \\
\hline Forage corn & 24 June 2007 & 907 & 0.60 & 0.30 & 2.12 & S78E & 77.5 & 0 & 49.5 & $14 . \mid$ \\
\hline Forage sorghum & 24 June 2007 & 847 & 0.60 & 0.30 & 1.90 & S78E & 80.3 & 0 & 53.6 & 16.8 \\
\hline Grain sorghum & 24 June 2007 & 1120 & 0.60 & 0.50 & 2.01 & SI69E & 74.8 & 0 & 22.9 & 76.1 \\
\hline
\end{tabular}

† CST $=$ Central Standard Time.

$\ddagger \mathrm{hC}=$ canopy height.

$\S w C=$ canopy width.

II $L A I=$ leaf area index.

$\# \theta_{\mathrm{R}}=$ radiometer zenith angle.

$\dagger \dagger \Phi_{R}=$ radiometer azimuth angle, with respect to crop row orientation.

$\neq \ddagger \theta_{S}=$ solar zenith angle.

$\S \S \Phi_{S}=$ solar aximuth angle, with respect to crop row orientation.

Conservation and Production Research Laboratory, Bushland, TX (35 $11^{\prime} \mathrm{N}$ lat., $102^{\circ} 06^{\prime} \mathrm{W}$ long., $1170 \mathrm{~m}$ elev. MSL). The climate is semiarid with a high evaporative demand of about $2600 \mathrm{~mm} \mathrm{yr}^{-1}$ (Class A pan evaporation) and low precipitation averaging $470 \mathrm{~mm} \mathrm{yr}^{-1}$. The climate is characterized by high solar radiation, generally low humidity, and strong advection of heat energy from the south and southwest. The soil is a Pullman clay loam (fine, mixed, super active, thermic torrertic Paleustolls) with slow permeability, having a dense B2 layer from about 0.15 - to $0.40-\mathrm{m}$ depth and a calcic horizon that begins at the 1.1-m depth (USDA-NRCS, 2009). Crops included grain and forage corn, grain and forage sorghum, cowpea, and upland cotton. Cultural practices were similar to those used for high-yield production in the Southern High Plains, and all crops were planted in rows spaced $0.76 \mathrm{~m}$ apart.

Plant measurements and destructive samples were taken periodically at key growth stages. The destructive sample areas were 1.0 to $1.5 \mathrm{~m}^{2}$. Leaf area was measured with a LI-COR ${ }^{1}$ leaf area meter (model LI-3100, Lincoln, NE), and the meter accuracy was verified periodically with a $0.005-\mathrm{m}^{2}$ standard disk. Plant height, width, and leaf area index (LAI) were related to growing

1 The mention of trade names of commercial products in this article is solely for the purpose of providing specific information and does not imply recommendation or endorsement by the USDA. degree days by fitting to fourth-order polynomials so that these parameters could be estimated between sample dates.

\section{Digital Photography}

Photographs were obtained during the 2009 season under clear skies with a Sony $\alpha 100$ digital camera $(23.6$ by $15.8 \mathrm{~mm}$ detector) and a Sony SH0006 lens (3.5-5.6 f-stop, 18-70 mm focal length) over grain corn on raised beds spaced $0.76 \mathrm{~m}$ and oriented approximately east-west $\left(\mathrm{S} 88^{\circ} \mathrm{E}\right)$ (Table 1$)$. The camera was mounted on a tripod with the lens $1.52 \mathrm{~m}$ above the top of the raised bed. The camera zenith view angle was varied using an adjustable jig that held the camera view axis parallel to the tripod arm. Photographs were acquired at zenith view angles of $0^{\circ}$, $30^{\circ}, 45^{\circ}$, and $60^{\circ}$, and azimuth view angles (relative to the crop rows) of $S 90^{\circ} \mathrm{W}, \mathrm{S} 45^{\circ} \mathrm{W}, 0^{\circ}$, and $\mathrm{S} 45^{\circ} \mathrm{E}$. For each zenith and azimuth view, two photographs were acquired where the camera focal lengths were 18 and $70 \mathrm{~mm}$. Thus a total of 26 photographs were obtained at each date. The zenith view angle, azimuth view angle, and crop row orientation were measured with a Kasper and Richter Alpin Pro prismatic sighting compass and clinometer (Kasper and Richter, Uttenreuth, Germany). The instrument has a $1^{\circ}$ precision and reported accuracy of $0.5^{\circ}$. The zenith view angle reported by the Kasper and Richter instrument was verified with a Johnson model 700 angle locator (Johnson Level and 


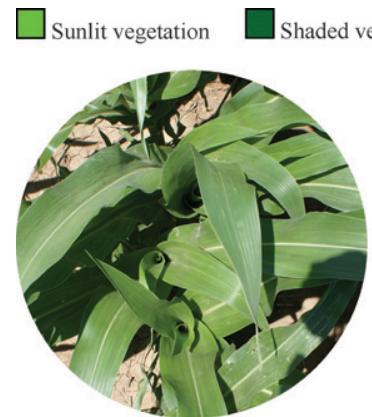

a.

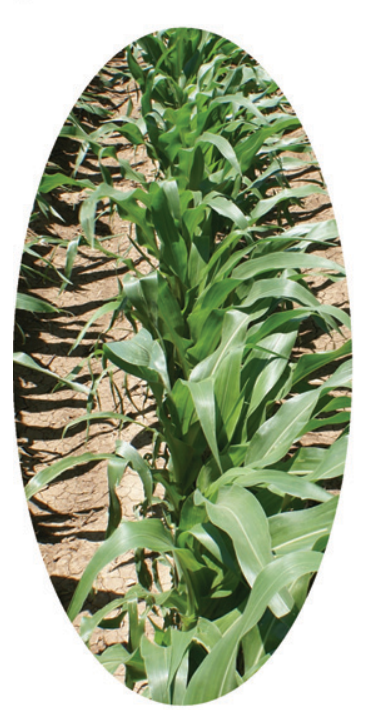

c.

Fig. 2. Images of corn on 15 June 2009 extracted to simulate circular and elliptical radiometer footprints. (a) nadir digital photograph; (b) nadir classified image; (c) oblique $\left(60^{\circ}\right)$ digital photograph; (d) oblique $\left(60^{\circ}\right)$ classified image.

Tool Manufacturing Co., Inc., Mequon, WI), and the azimuth view angle and row orientation were verified with a Silva model 426 sighting compass (Silva Sweden AB, Sollentuna, Sweden).

Photographs were obtained during the 2007 and 2008 seasons under clear skies with a Canon EOS 350D digital camera (22.2 by $14.8 \mathrm{~mm}$ detector) over grain and forage corn, grain and forage sorghum, cowpea, and upland cotton with various bed azimuth orientations (Table 1). The camera was held by hand approximately $1.6 \mathrm{~m}$ above the top of the raised bed and viewed the crop at zenith angles from $0^{\circ}$ to $81^{\circ}$ estimated by photogrammetry (focal lengths varied from 18 to $40 \mathrm{~mm}$ ). Camera azimuth view angles relative to the crop rows were $0^{\circ}$ and $90^{\circ}$.

The digital photographs were rectangular; however, a radiometer footprint was assumed circular or elliptical for nadir or off-nadir views, respectively (Fig. 2). Therefore, circular or elliptical sections were extracted from each photograph using LView Pro Image Processor (ver. 2006; CoolMoon Corp., Hallandale, $\mathrm{FL}$ ). The dimensions of a radiometer footprint are functions of the zenith view angle, radiometer height from the ground, and an assumed radiometer field-of-view that was constrained by the photograph. The maximum possible field of view was determined as follows. For an elliptical footprint with major semiaxis $a_{\mathrm{R}}$ and minor semiaxis $b_{\mathrm{R}}(\mathrm{m}$; Fig. 1$)$, it can be shown that

$$
a_{\mathrm{R}}=\frac{V_{\mathrm{R}}}{2}\left\{\tan \left[\theta_{\mathrm{R}}+\tan ^{-1}\left(\frac{1}{2 \mathrm{FOV}}\right)\right]-\tan \left[\theta_{\mathrm{R}}-\tan ^{-1}\left(\frac{1}{2 \mathrm{FOV}}\right)\right]\right\}[10]
$$

$$
b_{\mathrm{R}}=\frac{\sqrt{\left(a_{\mathrm{R}}+O_{\mathrm{R}}\right)^{2}+V_{\mathrm{R}}^{2}}}{2 \mathrm{FOV}}
$$

where $O_{\mathrm{R}}$ is the horizontal distance from the radiometer to the near quadrant of its footprint (m; point B in Fig. 1), $V_{\mathrm{R}}$ is the vertical distance of the radiometer from the ground $(\mathrm{m})$, and FOV is the radiometer field-of-view number (i.e., for 2:1 $\mathrm{FOV}, \mathrm{FOV}=2$, and the field-of-view and FOV as defined are inversely related). $O_{\mathrm{R}}$ was computed as

$$
O_{\mathrm{R}}=V_{\mathrm{R}} \tan \left[\theta_{\mathrm{R}}-\tan ^{-1}\left(\frac{1}{2 \mathrm{FOV}}\right)\right]
$$

With $2 a_{\mathrm{R}}$ constrained by the distance along the ground appearing in the photograph, the maximum $a_{\mathrm{R}}\left(a_{\mathrm{R}, \mathrm{MAX}}\right)$ was computed as

$$
a_{\mathrm{R}, \mathrm{MAX}}=\frac{V_{\mathrm{R}} H_{\mathrm{DET}}}{2 f \times \cos ^{2}\left(\theta_{\mathrm{R}}\right)}
$$

where $H_{\mathrm{DET}}$ is the height of the camera detector ( $\mathrm{mm}$ ), and $f$ is the camera focal length $(\mathrm{mm})$. Equating the right hand sides of Eq. [10] and [13] and simplifying results in a quadratic equation with FOV as the unknown variable. The positive root is then the minimum possible FOV for a radiometer footprint appearing within the photograph for the given parameters. The minimum FOV was rounded up to the next integer (which slightly reduced the actual field-of-view), a new $a_{\mathrm{R}}$ and $b_{\mathrm{R}}$ were determined by Eq. [10] and [11], respectively. The resulting radiometer footprint was extracted from the photograph using the LView extraction utility, where an extraction shape (i.e., circle or ellipse) was overlaid on the image. The LView program provides pixel coordinates along the sides of the image; therefore, the height of the circular or elliptical extraction shape (i.e., the radiometer footprint with height $2 a_{\mathrm{R}}$ ) was computed in terms of pixels as

$$
\zeta_{\mathrm{V}}=\frac{a_{\mathrm{R}} \zeta_{\mathrm{V}, \mathrm{MAX}}}{a_{\mathrm{R}, \mathrm{MAX}}}
$$

where $\zeta_{V}$ is the vertical number of pixels of the extraction shape, and $\zeta_{\mathrm{V}, \mathrm{MAX}}$ is the total vertical number of pixels contained in the image (e.g., $\zeta_{\mathrm{V}, \mathrm{MAX}}=2600$ pixels for a 10 megapixel camera with $2 / 3$ format). The horizontal number of pixels of the extraction shape $\left(\zeta_{\mathrm{H}}\right)$ was obtained by replacing $a_{\mathrm{R}}$ with $b_{\mathrm{R}}$ in Eq. [14]. The center of the extraction shape was estimated visually as the center of the crop row with pixel coordinates $\left(\zeta_{X}, \zeta_{Y}\right)$, and the upper left and lower right coordinates of the extraction shape were $\left(\zeta_{X}-1 / 2 \zeta_{H}, \zeta_{Y}-1 / 2 \zeta_{V}\right)$ and $\left(\zeta_{X}+1 / 2 \zeta_{H}, \zeta_{Y}+1 / 2 \zeta_{V}\right)$, respectively. The LView extraction utility (2006 version) did not provide for keyboard specification of coordinates; therefore, the location and size of the extraction shape had to be estimated visually using the coordinate tic marks along the sides of the image, which were in increments of 10 to 20 pixels. Although visual estimation of the upper left and lower right coordinates of the extraction shape introduced some error in the radiometer footprint area, this was probably less than $1 \%$ because all images were at least 800 pixels across, and since coordinates could be estimated visually to within 20 pixels, then $(20+20)^{2} / 400^{2}=$ 0.01 . The error associated with visual estimation of the extraction shape center coordinates $\left(\zeta_{\mathrm{X}}, \zeta_{\mathrm{Y}}\right)$ was more related to 
Table 2. Statistical parameters of agreement between modeled and observed components using digital photographs. See Fig. 3 and 4 for scatter plots.

\begin{tabular}{|c|c|c|c|c|c|c|c|c|}
\hline \multirow[b]{2}{*}{ Parameter } & \multicolumn{6}{|c|}{ Continuous Ellipse Model } & \multicolumn{2}{|c|}{ Clumping Index Model } \\
\hline & $f_{\text {VEG,SUN }} \S$ & $f_{\mathrm{VEG}, \mathrm{SHD}}$ I & $f_{\text {SOIL,SUN }} \#$ & $f_{\text {SOIL,SHD }}+\dagger$ & $f_{\text {VEG }}+\ddagger$ & $f_{\text {SOIL }} \S \S$ & $f_{\text {VEG }}+\ddagger$ & $f_{\text {SOIL }} \S \S$ \\
\hline$n=$ & 110 & 110 & 109 & 110 & 110 & 109 & 110 & 109 \\
\hline Obs. mean & 0.28 & 0.19 & 0.34 & 0.20 & 0.47 & 0.54 & 0.47 & 0.54 \\
\hline Obs. SD & 0.15 & 0.12 & 0.21 & 0.13 & 0.23 & 0.23 & 0.23 & 0.23 \\
\hline Pred. mean & 0.26 & 0.22 & 0.32 & 0.20 & 0.48 & 0.52 & 0.46 & 0.54 \\
\hline Pred. SD & 0.14 & 0.10 & 0.22 & 0.12 & 0.22 & 0.22 & 0.21 & 0.21 \\
\hline $\mathrm{E}_{\mathrm{C}} \dagger$ & 0.36 & 0.26 & 0.60 & 0.35 & 0.59 & 0.59 & 0.34 & 0.33 \\
\hline RMSE & 0.098 & 0.091 & 0.099 & 0.090 & 0.100 & 0.101 & 0.171 & 0.170 \\
\hline \% RMSE $\ddagger$ & $35 \%$ & $49 \%$ & $29 \%$ & $44 \%$ & $22 \%$ & $19 \%$ & $37 \%$ & $31 \%$ \\
\hline MAE & 0.077 & 0.075 & 0.073 & 0.069 & 0.079 & 0.081 & 0.129 & 0.131 \\
\hline$\%$ MAE $\ddagger$ & $28 \%$ & $40 \%$ & $22 \%$ & $34 \%$ & $17 \%$ & $15 \%$ & $28 \%$ & $24 \%$ \\
\hline MBE & -0.016 & 0.031 & -0.013 & -0.001 & 0.016 & -0.014 & -0.007 & 0.008 \\
\hline$\%$ MBE $\ddagger$ & $-5.6 \%$ & $16.6 \%$ & $-4.0 \%$ & $-0.5 \%$ & $3.3 \%$ & $-2.6 \%$ & $-1.5 \%$ & $1.4 \%$ \\
\hline
\end{tabular}

† EC is the modified coefficient of model efficiency (Legates and McCabe, 1999);

$$
E_{\mathrm{C}}=1-\frac{\sum_{i=1}^{n}\left|O_{\mathrm{i}}-P_{\mathrm{i}}\right|}{\sum_{i=1}^{n}\left|O_{\mathrm{i}}-\bar{O}\right|}
$$

where $\mathrm{Oi}$ and $\mathrm{Pi}$ are the observed and predicted (modeled) values, respectively.

$\ddagger$ Percentage of the observed mean.

$\S$ fVEG,SUN = area fraction of sunlit vegetation appearing in the radiometer footprint for a canopy penetrable to light.

If $\mathrm{fVEG}, \mathrm{SHD}=$ area fraction of shaded vegetation appearing in the radiometer footprint for a canopy penetrable to light.

\# fSOIL,SUN = area fraction of sunlit soil appearing in the radiometer footprint for a canopy penetrable to light.

†† fSOIL,SHD = area fraction of shaded soil appearing in the radiometer footprint for a canopy penetrable to light.

$\ddagger \ddagger \mathrm{fVEG}=$ area fraction of total vegetation appearing to a radiometer.

$\S \S$ fSOIL = area fraction of total soil appearing to a radiometer.

variability in plant location and canopy width along the row and hence was considered a component of random error.

The relative proportions of sunlit and shaded soil and vegetation $\left(f_{\text {VEG,SUN }}, f_{\text {VEG,SHD }}, f_{\text {SOIL,SUN }}, f_{\text {SOIL,SHD }}\right)$ were then determined by supervised classification (maximum likelihood with equal weights assigned to all classes) using MultiSpec ver. 3.1 Multispectral Image Data Analysis System (Purdue Univ., West Lafayette, IN). The supervised classification consisted of applying at least three training areas to each class, and the training areas were selected so that each class included the darkest to brightest pixels. For example, sunlit vegetation usually contained small amounts of specular reflection because nearly all photographs were obtained under clear skies. Specular reflection from sunlit vegetation could potentially be confused with sunlit soil; similarly, shaded vegetation and shaded soil may be difficult to distinguish (Fig. 2). The multiple training areas reduced classification errors, and overall reliability accuracy using resubstitution was greater than $96 \%$ for all classes. Model performance was evaluated by comparing $\mathrm{f}_{\text {VEG,SUN }}, \mathrm{f}_{\text {VEG,SHD }}, \mathrm{f}_{\text {SOIL,SUN }}, \mathrm{f}_{\text {SOIL,SHD }}$ computed by Eq. [4] to [7] to each respective component determined by supervised classification in the extracted digital photographs.

\section{RESULTS}

Model performance was evaluated for a wide range of vegetation cover, radiometer view zenith and azimuth angles, and solar zenith and azimuth angles (Table 1). This was important because a wide range of radiometer view and solar angles would be expected under center pivot irrigation systems, where crop rows were planted in a circular pattern, and radiometers aboard the center pivot may be at any field location for any solar position. Model performance was evaluated on the basis of root mean square error (RMSE), mean absolute error (MAE), mean bias error (MBE), and the modified coefficient of model efficiency $\left(E_{\mathrm{C}}\right.$, Legates and McCabe, 1999) (Table 2). For interpretation, $-\infty<E_{\mathrm{C}} \leq 1$, and $E_{\mathrm{C}}=0$ indicates that the mean of all observed values is as good a predictor as the model. If $E_{\mathrm{C}}$ $<0$, then the mean of the observed values is actually a better predictor than the model. Also, $\left(1-E_{\mathrm{C}}\right)$ indicates the absolute error between observed and predicted values as a percentage of the observed variance (Legates and McCabe, 1999). The continuous ellipse model was evaluated by comparing modeled and observed sunlit vegetation $\left(f_{\mathrm{VEG}, \mathrm{SUN}}\right)$, shaded vegetation $\left(f_{\mathrm{VEG}, \mathrm{SHD}}\right)$, sunlit soil $\left(f_{\mathrm{SOIL}, \mathrm{SUN}}\right)$, shaded soil $\left(f_{\text {SOIL,SHD }}\right)$, total vegetation $\left(f_{\mathrm{VEG}}\right)$, and total soil $\left(f_{\mathrm{SOIL}}\right)$ components. The clumping index model was evaluated on the basis of $f_{\mathrm{VEG}}$ and $f_{\text {SOIL }}$ only, which was the basis for comparison of performance with the continuous ellipse model. The statistical parameters of agreement as well as observed and predicted mean and standard deviations for each component were compiled in Table 2. Modeled vs. observed scatter plots of $f_{\mathrm{VEG}, \mathrm{SUN}}, f_{\mathrm{VEG}, \mathrm{SHD}}$, $f_{\text {SOIL,SUN }}$, and $f_{\text {SOIL,SHD }}$ were shown in Fig. 3 , as were modeled and observed scatter plots of $f_{\mathrm{VEG}}$ and $f_{\mathrm{SOIL}}$ for both the continuous ellipse and clumping index models (Fig. 4).

In all cases, $E_{\mathrm{C}}>0$, meaning that each model was a better predictor of each component compared with using the mean of all observed values. For each component, the continuous ellipse model resulted in RMSE $<0.10$ (<49\%), MAE < 0.08 (<40\%), and MBE from -0.016 to 0.031 ( -5.6 to $16.6 \%$ ), with each error also expressed as a percentage of the observed mean (Table 2, Fig. 3). Although RMSE and MAE were similar for each component, the respective error percentages were greater for the shaded components because observed means were smaller compared with 

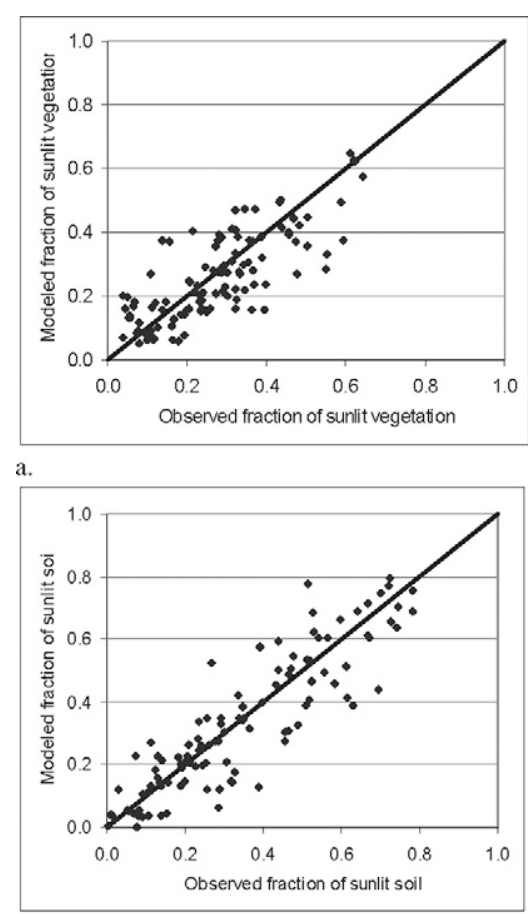

c.

Fig. 3. Modeled vs. observed fractional area of each component for the continuous ellipse model using digital photographs. (a) sunlit vegetation $\left(f_{\text {VEG,SUN }}\right)$; (b) shaded vegetation $\left(f_{\text {VEG,SHD }}\right)$; $(c)$ sunlit soil $\left(f_{\text {SOIL,SUN }}\right)$; (d) shaded soil $\left(f_{\text {SOIL,SHD }}\right)$. See Table 2 for statistical parameters of agreement.
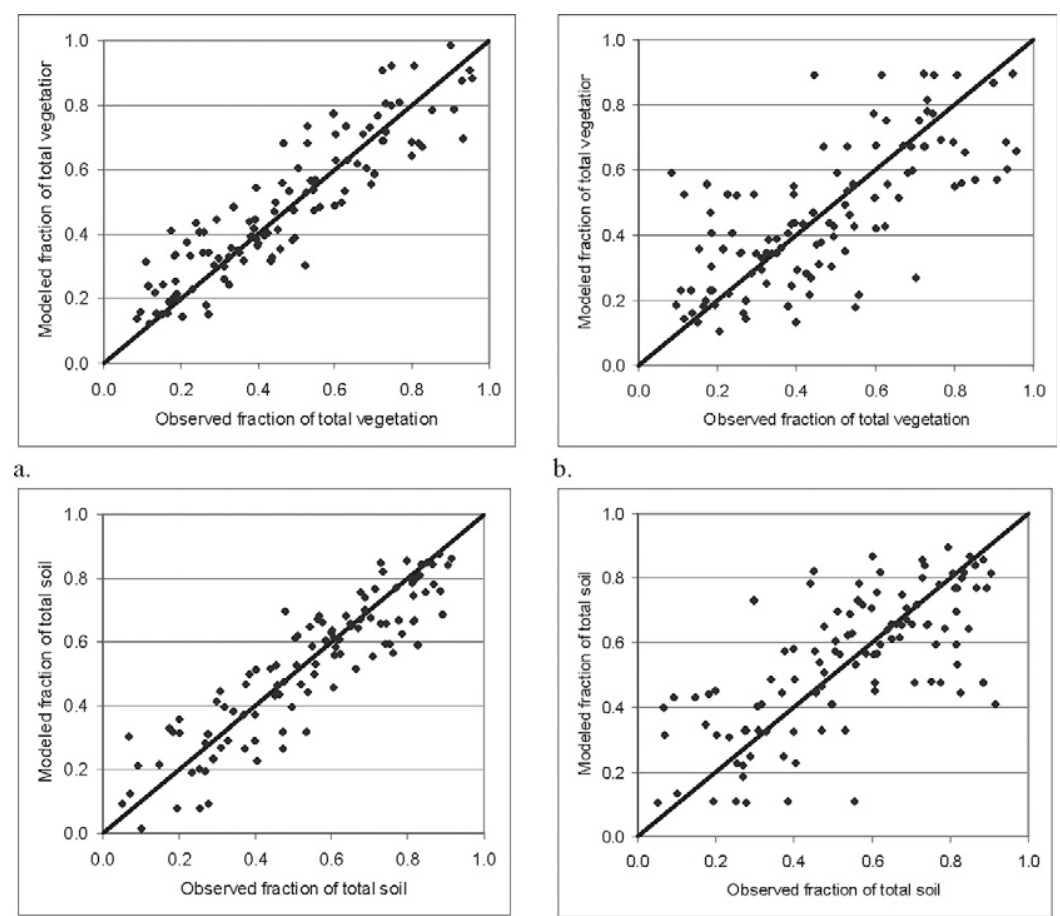

c.

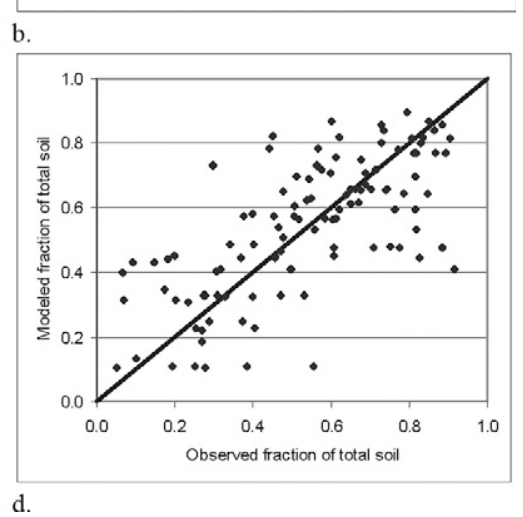

Fig. 4. Modeled vs. observed fractional area of total vegetation $\left(f_{\mathrm{VEG}}\right)$ and total soil $\left(f_{\text {SOIL }}\right)$ for the continuous ellipse and clumping index models using digital photographs. (a) Total vegetation-continuous ellipse model; (b) Total vegetationclumping index model; (c) Total soil-continuous ellipse model; (d) Total soilclumping index model. See Table 2 for statistical parameters of agreement. the sunlit components, which was expected because shaded components usually comprised less than $50 \%$ of all components except at high solar zenith angles. In all cases, RMSE was not much greater than MAE, indicating that the data was relatively free of outliers (Legates and McCabe, 1999). The greatest error resulted for $f_{\text {VEG,SHD }}$, which tended to be overestimated (positive MBE), whereas other components tended to be slightly underestimated (negative MBE). The $f_{\text {VEG,SHD }}$ had the least range of values compared with other components (i.e., it had the lowest observed mean and standard deviation).

For $f_{\mathrm{VEG}}$ and $f_{\text {SOIL }}$ as predicted by the continuous ellipse model, errors were slightly greater compared with their respective sunlit or shaded components, but error percentages were smaller $(<22 \%)$ because observed means were greater. For $f_{\mathrm{VEG}}$ and $f_{\mathrm{SOIL}}$, the continuous ellipse model resulted in about $60 \%$ less RMSE and MAE compared with the clumping index model. The MBE was no greater than 3.3\% for both models (Table 2, Fig. 4). The superior performance of the continuous ellipse model over the clumping index model implied that the greater complexity of a more physically based model was justified.

A sensitivity analysis was conducted where the sensitivity of each component to input parameters deemed as having the greatest uncertainty was assessed. Sensitivity $\left(S_{\mathrm{P}}\right)$ of a modeled component to an input parameter was computed following Zhan et al. (1996) as:

$S_{\mathrm{P}}=\left|\frac{Z_{-}-Z_{+}}{Z_{0}}\right|$

where $Z_{0}$ is the value of a modeled component $\left(f_{\mathrm{VEG}, \mathrm{SUN}}, f_{\mathrm{VEG}, \mathrm{SHD}}, f_{\text {SOIL,SUN }}, f_{\text {SOIL,SHD}}\right.$, $\left.f_{\mathrm{VEG}}, f_{\mathrm{SOIL}}\right)$ that results when an input parameter equals its base value, and $Z_{-}$and $Z_{+}$are the modeled components when an input parameter is increased or decreased a percentage of its base value, respectively. Input parameters deemed as having the greatest uncertainty included leaf area index (LAI), canopy height $\left(b_{\mathrm{C}}\right)$, canopy width $\left(w_{\mathrm{C}}\right)$, the radiometer zenith and azimuth view angles $\left(\theta_{R}\right.$ and $\Phi_{R}$, respectively), the vertical height of the radiometer above the ground $\left(V_{\mathrm{R}}\right)$, the horizontal distance of the radiometer from the nearest crop row $\left(\mathrm{P}_{\mathrm{R}}\right)$, and the radiometer field-ofview (FOV). The LAI, $h_{\mathrm{C}}$, and $w_{\mathrm{C}}$ of crop canopies typically have uncertainties of around $20 \%$, and LAI is likely to have the greatest uncertainty of the input parameters evaluated (Howell et al., 1997; Anderson et al., 2004). Therefore, input parameters were varied $\pm 20 \%$ of their base values, which were compiled in Table 3 . The input parameters $V_{\mathrm{R}}=3.0 \mathrm{~m}$ and FOV = 3 were selected based on probable values for radiometers aboard center pivots in the Southern High Plains, where the radiometer height was greater than the maximum height of corn, and the FOV resulted in footprint dimensions (i.e., $1.0 \mathrm{~m}$ at a nadir view) that were equal to or greater than the row spacing 
Table 3. Base values of input parameters (varied $\pm 20 \%$ ) used in the sensitivity analysis for small, medium, and large canopies, along with values of output variables $\left(Z_{0}\right)$ generated using the base input values.

\begin{tabular}{|c|c|c|c|}
\hline Variable & Small canopy & Medium canopy & Large canopy \\
\hline \multicolumn{4}{|l|}{ Base values of input parameters } \\
\hline Leaf area index $\left(\mathrm{LAl}, \mathrm{m}^{2} \mathrm{~m}^{-2}\right)$ & 0.57 & 1.13 & 1.70 \\
\hline Canopy height $\left(h_{C}, m\right)$ & 0.29 & 0.57 & 0.85 \\
\hline Canopy width $\left(w_{C}, m\right)$ & 0.19 & 0.38 & 0.57 \\
\hline Horizontal, perpendicular distance from radiometer to row center $\left(P_{R}, m\right)$ & 0.76 & 0.76 & 0.76 \\
\hline Vertical distance of the radiometer from the ground $\left(V_{R}, m\right)$ & 3.0 & 3.0 & 3.0 \\
\hline Radiometer field of view (FOV) & 3.0 & 3.0 & 3.0 \\
\hline Radiometer zenith angle $\left(\theta_{R}\right.$, degrees $)$ & 45.0 & 45.0 & 45.0 \\
\hline Radiometer azimuth angle ( $\Phi_{R}$, degrees) & S $45.0 \mathrm{~W}$ & S $45.0 \mathrm{~W}$ & S $45.0 \mathrm{~W}$ \\
\hline \multicolumn{4}{|l|}{ Base values $\left(Z_{0}\right)$ of modeled outputs } \\
\hline \multicolumn{4}{|l|}{ Continuous ellipse } \\
\hline$f_{\mathrm{VEG}, \mathrm{SUN}} \dagger$ & 0.20 & 0.42 & 0.57 \\
\hline$f_{\mathrm{VEG}, \mathrm{SHD}} \ddagger$ & 0.10 & 0.20 & 0.27 \\
\hline$f_{\text {SOIL,SUN }} \S$ & 0.56 & 0.15 & 0.05 \\
\hline$f_{\text {SOIL,SHD }}$ I & 0.14 & 0.24 & 0.11 \\
\hline$f_{\mathrm{VEG}} \#$ & 0.30 & 0.62 & 0.84 \\
\hline$f_{\text {SOIL }} \neq \ddagger$ & 0.70 & 0.38 & 0.16 \\
\hline Evaporation, $\mathrm{mm} \mathrm{h}^{-1}$ & 0.62 & 0.47 & 0.28 \\
\hline Transpiration, $\mathrm{mm} \mathrm{h}^{-1}$ & 0.06 & 0.24 & 0.42 \\
\hline \multicolumn{4}{|l|}{ Clumping index } \\
\hline$f_{\mathrm{VEG}} \#$ & 0.30 & 0.61 & 0.82 \\
\hline$f_{\text {SOIL }} \neq \ddagger$ & 0.70 & 0.39 & 0.18 \\
\hline Evaporation, $\mathrm{mm} \mathrm{h}^{-1}$ & 0.61 & 0.47 & 0.29 \\
\hline Transpiration, $\mathrm{mm} \mathrm{h}^{-1}$ & 0.06 & 0.24 & 0.42 \\
\hline
\end{tabular}

$\dagger f_{\mathrm{VEG}, \mathrm{SUN}}=$ area fraction of sunlit vegetation appearing in the radiometer footprint for a canopy penetrable to light.

$\ddagger f_{\mathrm{VEG}, \mathrm{SHD}}=$ area fraction of shaded vegetation appearing in the radiometer footprint for a canopy penetrable to light.

$\S f_{\text {SOIL,SUN }}=$ area fraction of sunlit soil appearing in the radiometer footprint for a canopy penetrable to light.

II $f_{\text {SOIL,SHD }}=$ area fraction of shaded soil appearing in the radiometer footprint for a canopy penetrable to light.

$\# f_{\mathrm{VEG}}=$ area fraction of total vegetation appearing to a radiometer.

$\ddagger \ddagger f_{\text {SOIL }}=$ area fraction of total soil appearing to a radiometer.

(0.76-1.0 $\mathrm{m}$ are typical). Since the amount of vegetation present will influence $S_{\mathrm{P}}$ (Li et al., 2005), it was evaluated for three canopy sizes (denoted small, medium, and large), where LAI = 0.57, 1.13, and $1.70 \mathrm{~m}^{2} \mathrm{~m}^{-2}$, respectively (Table 3 ). The $S_{\mathrm{P}}$ was evaluated for several solar zenith and azimuth angles ( $\pm 3 \mathrm{~h}$ of solar noon) and row orientations, but tended to be greatest for an east-west row orientation and for small solar zenith angles. Therefore, $S_{\mathrm{P}}$ values shown reflect conditions at the summer solstice (day of year 173) near solar noon (1245 h) at Bushland, TX, when the solar zenith angle reached its smallest value for the year.

For these summer conditions, $f_{\mathrm{VEG}, \mathrm{SUN}}$ had the greatest sensitivity to $\theta_{R}$, followed by LAI, for small and medium canopies, and $f_{\mathrm{VEG}, \mathrm{SUN}}$ was slightly more sensitive to LAI than $\theta_{\mathrm{R}}$ for the large canopy (Fig. 5). The $f_{\mathrm{VEG}, \mathrm{SHD}}$ parameter was most sensitive to $h_{C}$ and $w_{C}$ for all canopy sizes except for the small canopy, where $f_{\mathrm{VEG}, \mathrm{SHD}}$ was most sensitive to $\theta_{\mathrm{R}}$. The $f_{\text {SOIL,SUN }}$ parameter was most sensitive to $\theta_{\mathrm{R}}$ followed by LAI for a given canopy size, and these sensitivities increased with increasing canopy size. The $f_{\text {SOIL,SHD }}$ parameter was also most sensitive to $\theta_{\mathrm{R}}$, but sensitivities to LAI, $h_{\mathrm{C}}$, and $w_{\mathrm{C}}$ were similar. The largest sensitivities often resulted when expected values of components were small, which would be expected according to Eq. [15]. For example, $f_{\text {VEG,SUN }}$ and $f_{\text {VEG,SHD }}$ had larger sensitivities to some input parameters for smaller canopies, whereas $f_{\text {SOIL,SUN }}$ and $f_{\text {SOIL,SHD }}$ were more sensitive for larger canopies. The $f_{\text {SOIL,SUN }}$ component exhibited moderate sensitivity to $\Phi_{\mathrm{R}}$, but all components were relatively insensitive to $V_{\mathrm{R}}, P_{\mathrm{R}}$, and FOV. Although $\theta_{\mathrm{R}}$ may vary considerably for radiometers aboard mechanical move irrigation systems, the high sensitivities to $\theta_{R}$ will probably not degrade model performance because $\theta_{\mathrm{R}}$ can be controlled and measured with good accuracy and precision by inexpensive inclinometers (Haberland et al., 2010). However, model performance will probably be most impacted by uncertainties in LAI, $h_{\mathrm{C}}$, and $w_{\mathrm{C}}$. Operationally, LAI can be retrieved by reflectance-based indices, which generally require site-specific calibration, and $h_{\mathrm{C}}$ and $w_{\mathrm{C}}$ are usually known by direct measurement or knowledge of local crop agronomy (e.g., Anderson et al., 2004; Hunsaker et al., 2009).

The sensitivities of $f_{\mathrm{VEG}}$ and $f_{\mathrm{SOIL}}$ to each input parameter were compared for the continuous ellipse and clumping index models (Fig. 6). The input parameters $V_{\mathrm{R}}, P_{\mathrm{R}}$, and FOV do not apply to the clumping index model and were excluded from the respective graphs (i.e., $S_{\mathrm{P}}=0$ ). For the continuous ellipse model, $f_{\mathrm{VEG}}$ and $f_{\text {SOIL }}$ had sensitivities to $\theta_{\mathrm{R}}$ that were similar to their sunlit and shaded components; however, $f_{\mathrm{VEG}}$ and $f_{\mathrm{SOIL}}$ were somewhat less sensitive to LAI, $h_{\mathrm{C}}$, or $w_{\mathrm{C}}$. For the clumping index model, $f_{\mathrm{VEG}}$ and $f_{\text {SOIL }}$ were less sensitive to LAI, $\theta_{\mathrm{R}}$, and $\Phi_{\mathrm{R}}$, but more sensitive to $h_{\mathrm{C}}$ and $w_{\mathrm{C}}$ compared with the continuous ellipse model.

Although the scope of the present study was primarily limited to model development and testing, an additional sensitivity test was conducted to briefly demonstrate model application. Here, the sensitivities of evaporation and transpiration to the input 

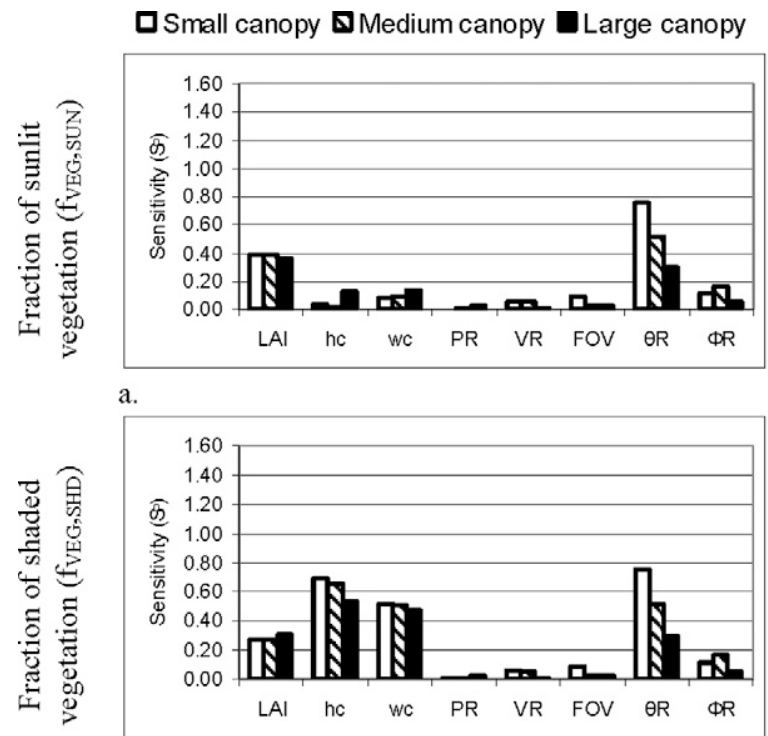

b.

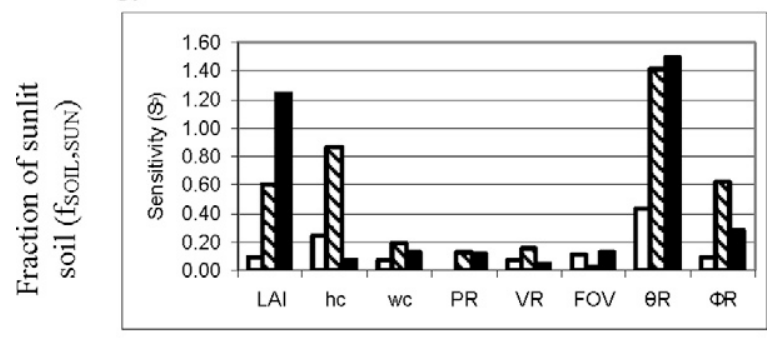

c.

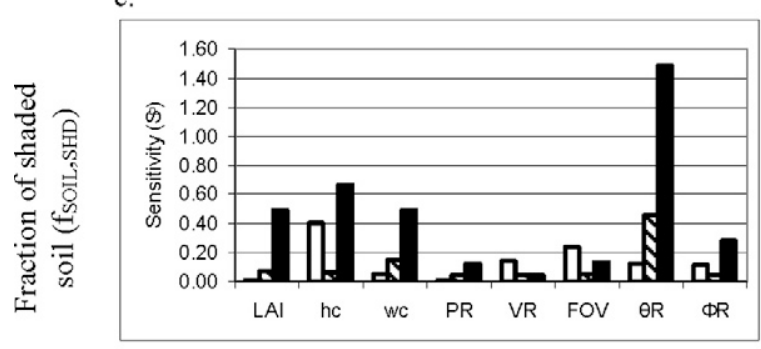

d.

Fig. 5. Sensitivity $\left(S_{P}\right)$ of each component for the continuous ellipse model when selected input parameters were varied $\pm 20 \%$. (a) sunlit vegetation ( $f_{V E G, S U N}$ ); (b) shaded vegetation ( $\left.f_{\text {VEG,SHD }}\right)$; (c) sunlit soil $\left(f_{\text {SOIL,SUN }}\right)$; (d) shaded soil $\left(f_{\text {SOIL,SHD }}\right)$. See Table 3 for base values of input and output parameters.

parameters (Table 3) were determined for both the continuous ellipse and clumping index models. Evaporation and transpiration were estimated with the two-source energy balance model of Kustas and Norman (1999), which requires $f_{\mathrm{VEG}}$ and $f_{\mathrm{SOIL}}$. Both evaporation and transpiration were somewhat more sensitive to LAI, $h_{\mathrm{C}}$, and $w_{\mathrm{C}}$ compared with $f_{\mathrm{VEG}}$ and $f_{\mathrm{SOIL}}$; however, evaporation and transpiration were much less sensitive to $\theta_{\mathrm{R}}$ (Fig. 6). The greater sensitivities to LAI, $h_{\mathrm{C}}$, and $w_{\mathrm{C}}$ were related more to computed resistances to flux transfer used in the twosource energy balance model rather than computed $f_{\mathrm{VEG}}$ and $f_{\text {SOIL }}$ (Kustas and Norman, 1999; Li et al., 2005); furthermore, both the continuous ellipse and clumping index models resulted in very similar sensitivities for each input parameter. Hence, the relative merits of each model were difficult to evaluate based on an application where other physical processes were present. This pointed to the need for further research where applications such as multi-layered energy balance models, crop biophysical models, or radiative transfer models (e.g., Campbell and Norman, 1998; Fitzgerald et al., 2005) can be investigated in more detail.

\section{DISCUSSION}

The continuous ellipse model resulted in better prediction of $f_{\mathrm{VEG}}$ and $f_{\mathrm{SOIL}}$ compared with the clumping index model (Table 2, Fig. 4). These differences in model performance were the result of the relative scale of the radiometer footprint dimensions.

The error observed using the clumping index model increased sharply as the radiometer footprint dimensions (i.e., semiaxes $a_{\mathrm{R}}$ and $\left.b_{\mathrm{R}}\right)$ decreased below the row spacing $(0.76 \mathrm{~m}$ in this case); however, error observed for the continuous ellipse model was fairly independent of the radiometer footprint dimensions (data not shown). The implicit scale of the clumping index model contains one complete row width; therefore, the clumping index model is independent of the radiometer footprint size or the footprint position relative to a crop row. At relatively small scales, where the footprint dimensions are similar to or smaller than the crop row spacing, the footprint dimension and position relative to the crop row (as influenced by $V_{\mathrm{R}}, P_{\mathrm{R}}$, and FOV) can have substantial impact on $f_{\mathrm{VEG}}$ and $f_{\mathrm{SOIL}}$ within the footprint. For example, a circular footprint with a diameter $50 \%$ of the row spacing viewing a canopy with $50 \%$ vegetation cover would see pure $f_{\text {SOIL }}$ when pointed over the furrow, and mostly $f_{\mathrm{VEG}}$ when pointed over the canopy. The clumping index model does not account for radiometer footprint dimensions or position relative to the crop row; therefore, greater error would be expected for relatively small footprint dimensions. An additional sensitivity analysis (not shown) where $V_{\mathrm{R}}=1.5 \mathrm{~m}$ and FOV $=$ 5 (resulting in footprint dimensions smaller than the crop row spacing) indicated that each component computed using the continuous ellipse model was much more sensitive to $V_{\mathrm{R}}, P_{\mathrm{R}}$, and $\Phi_{\mathrm{R}}$ for LAI values of 0.57 and 1.13 but not for $1.70 \mathrm{~m}^{2} \mathrm{~m}^{-2}$. These sensitivities were similar in magnitude to those where $\theta_{R}$ and LAI were the input parameters, which were also similar in magnitude to those shown in Fig. 5 and 6. Consequently, even when $f_{\mathrm{VEG}}$ and $f_{\mathrm{SOIL}}$ are not required to be resolved into their sunlit and shaded components, the continuous ellipse model is advantageous over the clumping index model when the radiometer footprint scale is similar to or smaller than the row spacing. However, given the resulting sensitivities to $V_{\mathrm{R}}, P_{\mathrm{R}}$, and $\Phi_{\mathrm{R}}$, we recommend a radiometer deployment that results in at least two crop rows appearing in the footprint.

Modeled fractional area components were generally most sensitive to $\theta_{\mathrm{R}}, \mathrm{LAI}, h_{\mathrm{C}}$, and $w_{\mathrm{C}}$ when the radiometer footprint dimensions were equal to or greater than the row spacing. The uncertainty of $\theta_{R}$ would not be expected to be greater than about $1^{\circ}$, provided that an inclinometer (which is relatively inexpensive and readily available) was used when deploying a radiometer (Haberland et al., 2010). In applications where only radiometric temperature is measured (e.g., Wanjura et al., 1995; Peters and Evett, 2007), field-averaged LAI, $h_{\mathrm{C}}$, and $w_{\mathrm{C}}$ values could be assumed based on knowledge of local crop growth and development, which could be related to simple growth models such as accumulated growing degree days. However, even where soil texture and management strategies were known to be highly uniform throughout a field, LAI has typically been observed to vary \pm 10 to $30 \%$ of the field mean for crops under irrigation such as corn (Howell et al., 1995a), grain sorghum (Howell et al., 1997), winter wheat (Triticum aestivum 

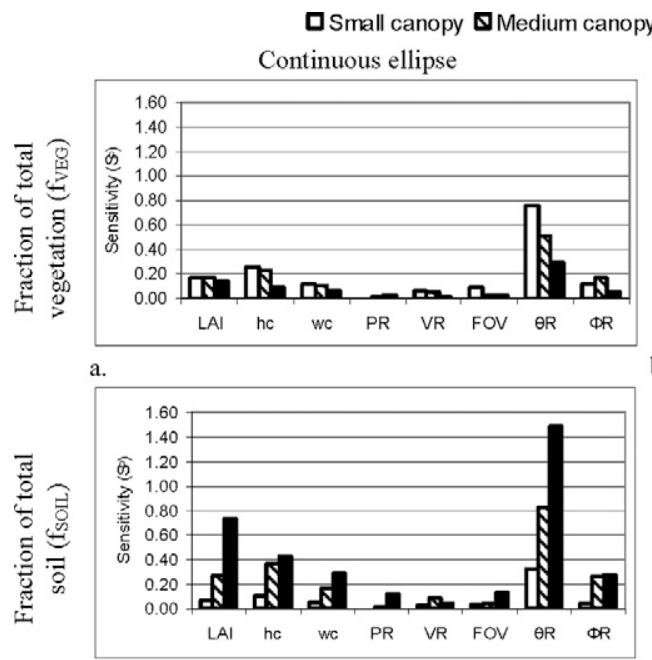

c.

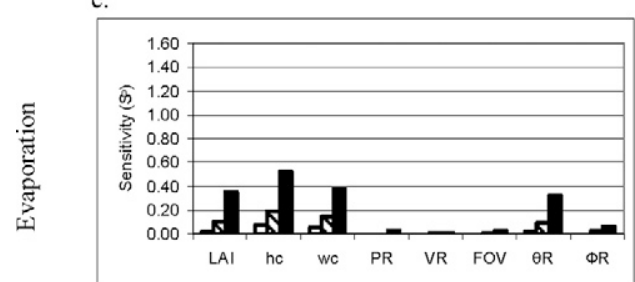

e.

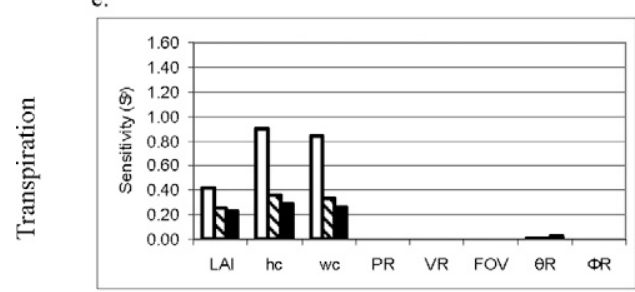

g.

Fig. 6. Sensitivity $\left(S_{P}\right)$ of components for the continuous ellipse and clumping index models when selected input parameters were varied $\pm 20 \%$. (a) total vegetation ( $f_{\text {VEG }}$ ) for continuous ellipse model; $(b)$ total vegetation ( $f_{\text {VEG }}$ ) for clumping index model; $(c)$ total soil $\left(f_{\text {solL }}\right)$ for continuous ellipse model; (d) total soil ( $f_{\text {solL }}$ ) for clumping index model; (e) evaporation for continuous ellipse model; (f) evaporation for clumping index model; (g) transpiration for continuous ellipse model; (h) transpiration for clumping index model. See Table 3 for base values of input and output parameters.

L.)(Howell et al., 1995b), and cotton (Howell et al., 2004). Most remote sensing applications include measurement of reflectance bands suitable for vegetation indices (e.g., Hunsaker et al., 2009); therefore, spatially distributed LAI can be estimated, but these are still subject to uncertainties of up to 20\% (Anderson et al., 2004). From Fig. 5, modeled fractional area components had a wide range of sensitivities when LAI was varied $\pm 20 \%$, with an average $S_{\mathrm{P}}$ of around 0.40 . Therefore, root mean square errors (RMSE) of at least $40 \%$ of observed means should be expected between modeled and observed components, and RMSE for $f_{\mathrm{VEG}, \mathrm{SUN}}, f_{\mathrm{VEG}, \mathrm{SHD}}$ $f_{\text {SOIL,SUN }}$, and $f_{\text {SOIL,SHD }}$ were 29 to $49 \%$ of their observed means (Table 2). Similarly from Fig. 6, average $S_{\mathrm{P}}$ was around 0.30 when LAI was varied $\pm 20 \%$, and the RMSE for $f_{\text {VEG }}$ and $f_{\text {SOIL }}$ using the continuous ellipse model were 22 and $19 \%$, respectively, of their observed means (Table 2). These RMSE were construed to indicate reasonable model performance.

The continuous ellipse model tended to overestimate $f_{\mathrm{VEG}, \mathrm{SHD}}$, where MBE was greatest compared with other components (Table 2). This can be seen for observed $f_{\mathrm{VEG}, S H D}<0.2$ (Fig. 3), which were mostly observations of corn canopies with low LAI. For these conditions, a greater proportion of the lower portion of the canopy was visible compared with larger corn plants or other vegetation. Hence, a greater proportion of shaded vegetation would be expected to be visible if vegetation within the canopy envelope was randomly distributed. Corn leaves, however, tend to be distributed toward the top of the plant, resulting in a greater proportion of sunlit leaves being visible. This somewhat violated the assumption of randomly distributed vegetation within the canopy envelope, which was otherwise required for the simple exponential extinction model of Eq. [8], and resulted in overestimates of $f_{\mathrm{VEG}, \mathrm{SHD}}$. Somewhat related to vegetation distribution within the canopy, other sources of model error may have been associated with assumptions about the leaf angle distribution, which greatly impacts the transmission of radiation through plant canopies. This was quantified through the extinction coefficient $[\kappa(\theta)]$ used in Eq. [8]. In this study, $\kappa(\theta)$ was computed based on the spherical leaf angle distribution function, where the ratio of projected leaf area on horizontal and vertical surfaces $(x)$ was assumed unity, which was deemed "a good approximation to real plant canopies" (Campbell and Norman, 1998). However, the $x$ parameter given for maize may vary 0.76 to 2.52 (Table 15.1 in Campbell and Norman, 1998). Nonetheless, varying the $x$ parameter through this range for different canopy sizes did not improve model performance, which supported the spherical leaf angle distribution function as being fairly robust when computing $\kappa(\theta)$.

\section{CONCLUSIONS}

A geometric model for row crops, termed the continuous ellipse model, was developed to compute the relative proportions of sunlit vegetation, shaded vegetation, sunlit soil, and shaded soil appearing in a circular or elliptical radiometer field-of-view, where crop rows were modeled as continuous ellipses. Quantifying the relative proportions of these components is important to determine canopy biophysical properties and to estimate the energy balance of the soil-plant-atmosphere continuum; these have important applications in remote sensing for crop management. The relative proportions of modeled components were compared to those determined by supervised classification of digital photographs. The root mean squared errors (RMSE) and mean bias errors (MBE) between observed and modeled components were 29 to $49 \%$ and -5.6 to $16.6 \%$, respectively, of the observed means, with the greatest RMSE and MBE resulting for shaded vegetation, which tended to be overestimated for corn with low leaf area index (LAI). This was probably related to the assumption that vegetation within the canopy envelope is randomly distributed when computing beam radiation transmittance based on exponential extinction, whereas corn plants tend to have greater proportions of vegetation toward the top.

The continuous ellipse model was compared to the clumping index approach, which is commonly used to estimate the proportions of total vegetation and soil for a radiometer view or solar zenith angle. The clumping index approach does not account for radiometer footprint dimensions and does not resolve 
vegetation and soil into their sunlit or shaded components. The continuous ellipse model resulted in RMSE and MBE of 22 and $3.3 \%$, respectively, for total vegetation; the RMSE and MBE for total soil were 19 and $-2.6 \%$, respectively. The clumping index approach resulted in respective RMSE and MBE of 37 and $-1.5 \%$ for total vegetation; the respective RMSE and MBE for total soil were 31 and $1.4 \%$. The larger scatter observed using the clumping index approach mainly resulted when radiometer footprint dimensions were similar to the crop row spacing.

A sensitivity analysis indicated that both the continuous ellipse and clumping index models were generally most sensitive to the radiometer view zenith angle $\left(\theta_{R}\right)$, canopy height $\left(h_{\mathrm{C}}\right)$, canopy width $\left(w_{\mathrm{C}}\right)$, and LAI. However, the continuous ellipse model was also sensitive to parameters that determine the radiometer footprint dimensions (deployment height, distance to crop rows, and field-of-view) when these were similar to the crop row spacing. This further explained the greater RMSE resulting with the clumping index model compared with the continuous ellipse model, where the former does not account for radiometer footprint dimensions. The $\theta_{R}$ can usually be controlled and accounted for with an inexpensive inclinometer, and $h_{\mathrm{C}}$ and $w_{\mathrm{C}}$ can be measured or estimated from knowledge of crop agronomy. However, LAI uncertainly is often $\pm 20 \%$, which probably contributed the most to model errors and will probably be at least $20 \%$ according to the sensitivity analysis. Therefore, the RMSE and MBE reported herein were deemed to indicate acceptable performance of the continuous ellipse model. Since the continuous ellipse model was sensitive to deployment height, distance to crop rows, and field-of-view when the radiometer footprint dimensions were similar to crop row spacing, we recommend radiometer deployment where at least two crop rows appear in the footprint.

\section{ACKNOWLEDGMENTS}

This research was supported by the Ogallala Aquifer Program and USDA-ARS National Program 211, Water Availability and Watershed Management. We thank the numerous biological technicians and student workers for their meticulous and dedicated efforts in executing experiments and obtaining and processing data.

\section{APPENDIX I. Computation of chord locations in an elliptical radiometer footprint.}

The areas of the sunlit soil, shaded soil, and canopy components in the radiometer footprint (Fig. 1) represent areas bound by chords in an ellipse. These areas are required for Eq. [1], [2], and [3]. These areas can be computed from $a_{\mathrm{R}}, b_{\mathrm{R}}, \Phi_{\mathrm{R}}$, and the relative position of the chord (i.e., $\mathrm{H}_{1}, \mathrm{H}_{2}, \mathrm{H}_{3}$, or $\mathrm{H}_{4}$ ) along the major or minor axis.

The chord distances $\mathrm{H}_{1}$ and $\mathrm{H}_{2}(\mathrm{~m})$ are computed as:

$$
\begin{aligned}
& \mathrm{H}_{1}=V_{\mathrm{R}} \tan \left(\theta_{1}\right)-O_{\mathrm{R}} \\
& \mathrm{H}_{2}=V_{\mathrm{R}} \tan \left(\theta_{2}\right)-O_{\mathrm{R}}
\end{aligned}
$$

where $\theta_{1}$ and $\theta_{2}$ are the zenith angles formed by the near and far, respectively, radiometer field-of-view boundaries of the canopy (Fig. 1). These angles are computed by considering a line that passes through the radiometer at a point $\left(x_{\mathrm{C}}, y_{\mathrm{C}}\right)$, and that is tangent to the canopy ellipse at point $\left(x_{\mathrm{T}}, y_{\mathrm{T}}\right)$, where the origin is the canopy ellipse center. Combining the equations for the line and the canopy ellipse at $\left(x_{\mathrm{T}}, y_{\mathrm{T}}\right)$, it can be shown that

$$
\begin{aligned}
& \left(y_{\mathrm{C}}^{2} a_{\mathrm{C}}^{2}-a_{\mathrm{C}}^{4}\right) \tan ^{4}\left(\theta_{1,2}\right)-\left(2 x_{\mathrm{C}} y_{\mathrm{C}} a_{\mathrm{C}}^{2}\right) \tan ^{3}\left(\theta_{1,2}\right)+ \\
& \left(y_{\mathrm{C}}^{2} b_{\mathrm{CR}}^{2}+x_{\mathrm{C}}^{2} a_{\mathrm{C}}^{2}-2 b_{\mathrm{CR}}^{2} a_{\mathrm{C}}^{2}\right) \tan ^{2}\left(\theta_{1,2}\right)- \\
& \left(2 x_{\mathrm{C}} y_{\mathrm{C}} b_{\mathrm{CR}}^{2}\right) \tan \left(\theta_{1,2}\right)+\left(x_{\mathrm{C}}^{2} b_{\mathrm{CR}}^{2}-b_{\mathrm{CR}}^{4}\right)=0
\end{aligned}
$$

which is a quartic equation of the form $A x^{4}+B x^{3}+C x^{2}+D x$ $+E=0$, and $y_{\mathrm{C}}=V_{\mathrm{R}}-a_{\mathrm{C}}, x_{\mathrm{C}}=P_{\mathrm{R}} / \sin \left(\Phi_{\mathrm{R}}\right)$, and $b_{\mathrm{CR}}=b_{\mathrm{C}}{ }^{\prime}$ $\sin \left(\Phi_{\mathrm{R}}\right)$, where $P_{\mathrm{R}}$ and $V_{\mathrm{R}}$ are the horizontal (perpendicular) and vertical distances $(\mathrm{m})$, respectively, from the radiometer to the row center. Solution of Eq. [A3] will yield four roots; these are $\pm \tan \left(\theta_{1}\right)$ and $\pm \tan \left(\theta_{2}\right)$.

The chord distances $\mathrm{H}_{3}$ and $\mathrm{H}_{4}$ were derived as:

$$
\begin{aligned}
& \mathrm{H}_{3}=\frac{P_{\mathrm{R}}-X_{\mathrm{S}}-\left(a_{\mathrm{C}}+Y_{\mathrm{S}}\right) \tan \left(\theta_{\mathrm{SP}}\right)}{\sin \left(\varphi_{\mathrm{R}}\right)}-O_{\mathrm{R}} \\
& \mathrm{H}_{4}=\frac{P_{\mathrm{R}}+X_{\mathrm{S}}-\left(a_{\mathrm{C}}-Y_{\mathrm{S}}\right) \tan \left(\theta_{\mathrm{SP}}\right)}{\sin \left(\varphi_{\mathrm{R}}\right)}-O_{\mathrm{R}}
\end{aligned}
$$

where $X_{\mathrm{S}}$ and $Y_{\mathrm{S}}$, are the horizontal and vertical distances $(\mathrm{m})$, respectively, from the canopy ellipse origin to the tangent of the solar beam, and $\theta_{S P}$ is the projected solar zenith angle along the radiation path relative to the canopy ellipse. Expressions for $X_{\mathrm{S}}$ and $Y_{\mathrm{S}}$ were derived by combining the equation of the canopy ellipse with the slope of the line tangent to the canopy ellipse (i.e., the solar beam), where the point $\left(X_{\mathrm{S}}, Y_{\mathrm{S}}\right)$ is common to both equations, resulting in:

$$
\begin{aligned}
& X_{\mathrm{S}}=\frac{b_{\mathrm{C}}}{\sqrt{1+\frac{a_{\mathrm{C}}^{2}}{b_{\mathrm{C}}^{2}} \tan ^{2} \theta_{\mathrm{SP}}}} \\
& Y_{\mathrm{S}}=\frac{a_{\mathrm{C}}^{2}}{b_{\mathrm{C}}^{2}} X_{\mathrm{S}} \tan \theta_{\mathrm{SP}}
\end{aligned}
$$

and

$$
\tan \theta_{\mathrm{SP}}=\tan \theta_{S}\left|\sin \varphi_{\mathrm{S}}\right|
$$

where $\theta_{S}$ is the solar zenith angle and $\Phi_{S}$ is the solar azimuth angle relative to the crop row (i.e., $\Phi_{S}=0^{\circ}$ and $90^{\circ}$ when the sun is parallel and perpendicular to the crop row, respectively). The signs of $\theta_{\mathrm{SP}}$ and $Y_{\mathrm{S}}$ depend on the sun's position, where the sign convention adopted has $\theta_{S P}$ and $Y_{S}$ as positive (negative) for the sun to the left (right) of the canopy in Fig. 1, and $X_{\mathrm{S}}$ is always positive.

It should be noted that all $\mathrm{H}_{\mathrm{N}}$ will increase without bound as $\Phi_{R} \rightarrow 0^{\circ}$. To avoid this, we imposed that $45^{\circ} \leq \Phi_{R}<90^{\circ}$ (e.g., $\Phi_{\mathrm{R}}=0^{\circ}$ became $\left.\Phi_{\mathrm{R}}=90^{\circ}\right)$. This required $O_{\mathrm{R}}$ to be multiplied by $\tan \left(\Phi_{\mathrm{R}}\right)$ in Eq. [A4] and [A5] and switching the major and minor axes of the radiometer footprint when computing the areas bounded by $\mathrm{H}_{\mathrm{N}}$.

The above computations for all $\mathrm{H}_{\mathrm{N}}$ can be extended to multiple canopy rows that may either appear directly or cast shadows in the radiometer footprint. Assuming that the row spacing and canopy height and width are the same for all canopy rows, the same procedure is followed except a different $P_{\mathrm{R}}$ value must be used for each row $(i)$, which is computed as

$$
P_{\mathrm{R}}(i)=P_{\mathrm{R}}+(r / 2)\left(2 i-N_{\mathrm{R}}-1\right)
$$


where $r$ is the row spacing $(\mathrm{m}), N_{\mathrm{R}}$ is the total number of rows, and all other terms are as defined previously. The size of $N_{\mathrm{R}}$ can be as large as needed to ensure that all rows influencing the radiometer are accounted for, because any $\mathrm{H}_{\mathrm{N}}$ appearing beyond the radiometer footprint will result in zero area. For $N_{\mathrm{R}}$, we determined the number of rows actually appearing in the footprint, doubled it and added one to make it an odd number, and added four additional rows:

$$
N_{\mathrm{R}}=2 \times \operatorname{ROUNDUP}\left[2 T_{\mathrm{R}} \sin \left(\varphi_{\mathrm{R}}\right) / r\right]+5
$$

where $T_{\mathrm{R}}$ is the distance from the footprint center, along the major axis, to a line tangent to the footprint forming angle $\Phi_{R}$ with the major axis $(\mathrm{m})$, and $T_{\mathrm{R}}$ was derived as

$$
T_{\mathrm{R}}=\frac{a_{\mathrm{R}}}{\sqrt{1+\frac{b_{\mathrm{R}}^{2}}{a_{\mathrm{R}}^{2} \tan ^{2}\left(\varphi_{\mathrm{R}}\right)}}}\left(1+\frac{b_{\mathrm{R}}^{2}}{a_{\mathrm{R}}^{2} \tan ^{2}\left(\varphi_{\mathrm{R}}\right)}\right)
$$

With all $\mathrm{H}_{\mathrm{N}}(i)$ computed for each canopy row $i$, it must be determined which $\mathrm{H}_{\mathrm{N}}(i)$ are obscured by adjacent canopy rows. Consider a canopy $(i+1)$ to the left of a canopy $(i)$, where canopy (i), the radiometer, and the solar position are represented by Fig. 1. The far side of canopy ( $i$ ) may obscure the sunlit-shaded soil boundary or the canopy boundary on the near side of canopy (i+1). This is expressed as $\mathrm{H}_{2}(i)>\mathrm{H}_{3}(i+1)$ or $\mathrm{H}_{2}(i)>\mathrm{H}_{1}(i+1)$, respectively. If any of these conditions exist, then each $\mathrm{H}_{\mathrm{N}}(i+1)$ is set equal to $\mathrm{H}_{2}(i)$. Similarly, if the radiometer viewed canopy (i) from the left in Fig. 1, then the far side of canopy (i+1) may obscure the sunlit-shaded soil boundary or the canopy boundary on the near side of canopy $(i)$. This is expressed as $\mathrm{H}_{1}(i+1)<$ $\mathrm{H}_{4}(i)$ or $\mathrm{H}_{1}(i+1)<\mathrm{H}_{2}(i)$, respectively. If any of these conditions exist, then each $\mathrm{H}_{\mathrm{N}}(i)$ is set equal to $\mathrm{H}_{1}(i+1)$.

\section{APPENDIX 2. Path length fraction $\left(P_{L}\right)$ and multiple row factor $\left(M_{R}\right)$.}

The path length fraction $\left(P_{\mathrm{L}}\right)$ and multiple row factor $\left(M_{\mathrm{R}}\right)$ were derived to account for the nonrandom distribution of vegetation in row crops when computing the transmittance of radiation through a canopy. From Eq. [8], transmittance may be either in terms of the solar angle or the radiometer view angle. The path length fraction $\left(P_{\mathrm{L}}\right)$ is the length fraction relative to vertical for a radiation path through a canopy modeled as a continuous ellipse. For uniform canopies, $P_{\mathrm{L}}=1 / \cos (\theta)$ where $\theta$ is the solar zenith angle $\left(\theta_{S}\right)$ or radiometer view zenith angle $\left(\theta_{R}\right)$, but for row crops, $P_{\mathrm{L}}$ also depends on the solar and radiometer azimuth view angles relative to the crop row $\left(\Phi_{S}\right.$ and $\Phi_{R}$, respectively) and the canopy width. $P_{\mathrm{L}}$ is defined as (Fig. A1):

$$
P_{\mathrm{L}} \equiv \frac{\sqrt{x^{2}+y^{2}+z^{2}}}{a_{\mathrm{C}}}
$$

where

$$
\begin{aligned}
& y=\frac{a_{\mathrm{C}} b_{\mathrm{C}}}{\sqrt{a_{\mathrm{C}}^{2} \tan ^{2}\left(\theta_{\mathrm{P}}\right)+b_{\mathrm{C}}^{2}}} \\
& x=y \tan \left(\theta_{\mathrm{P}}\right)
\end{aligned}
$$
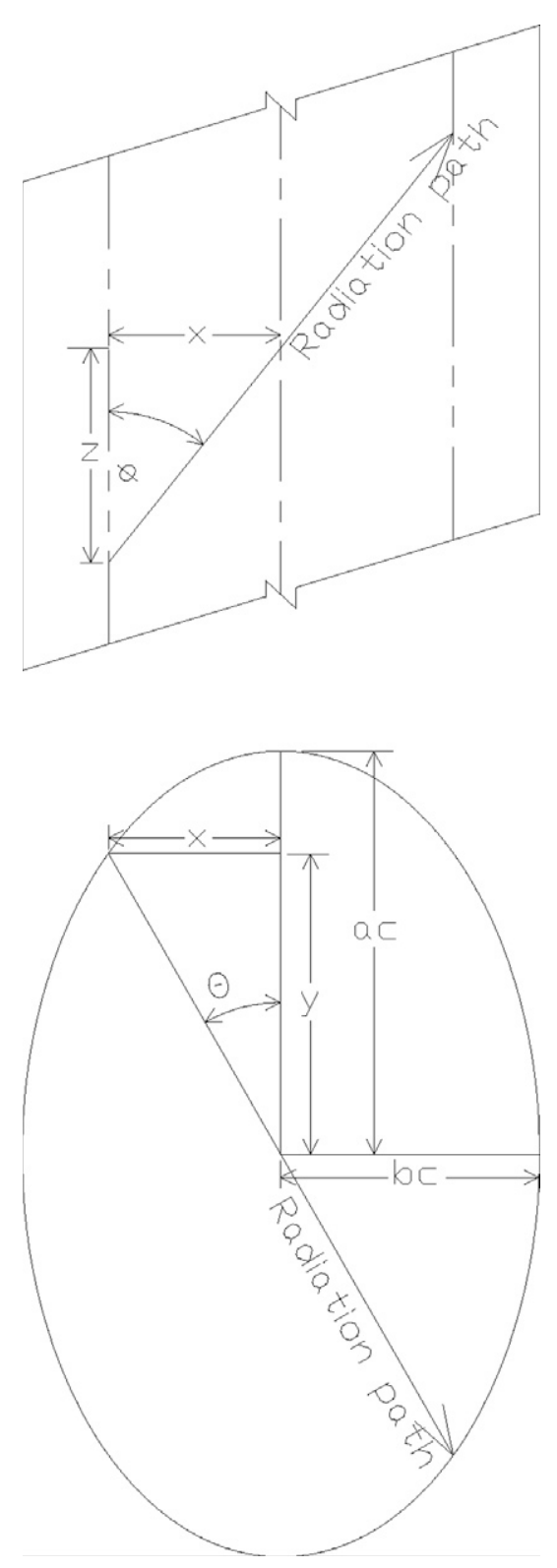

Fig. Al. Parameters used to compute $P_{L}$ (path length fraction) of a radiation path through a canopy modeled as a continuous ellipse.

$$
z=\frac{x}{\tan (\varphi)}
$$

where $\theta_{\mathrm{P}}$ is the projected zenith angle along the radiation path relative to the canopy ellipse; for solar radiation, $\theta_{\mathrm{P}}$ becomes $\theta_{S P}$ and is given by Eq. [A8], and for a radiometer view, $\theta_{\mathrm{P}}$ becomes $\theta_{R P}$ and $\tan \theta_{R P}=\tan \theta_{R}\left|\sin \Phi_{R}\right|$.

For large $\theta$, or $h_{\mathrm{C}}$ greater than crop row spacing $(r)$, the path of radiation will likely propagate through multiple rows, which was accounted for by the multiple row factor $\left(M_{\mathrm{R}}\right)$. Consider three crop rows, modeled as continuous ellipses, with row spacing $r$, and major and minor semiaxes $a_{\mathrm{C}}$ and $b_{\mathrm{C}}$, respectively (Fig. A2). Beginning with the row on the left, there are $n=1$ and $n=2$ adjacent rows to the right, each with a corresponding tangent. Each tangent contacts the far left ellipse a distance $X_{\mathrm{CR}}(n)$ from its center, derived as

$$
X_{\mathrm{CR}}(n)=\frac{2 b_{\mathrm{C}}^{2}}{n \times r}
$$




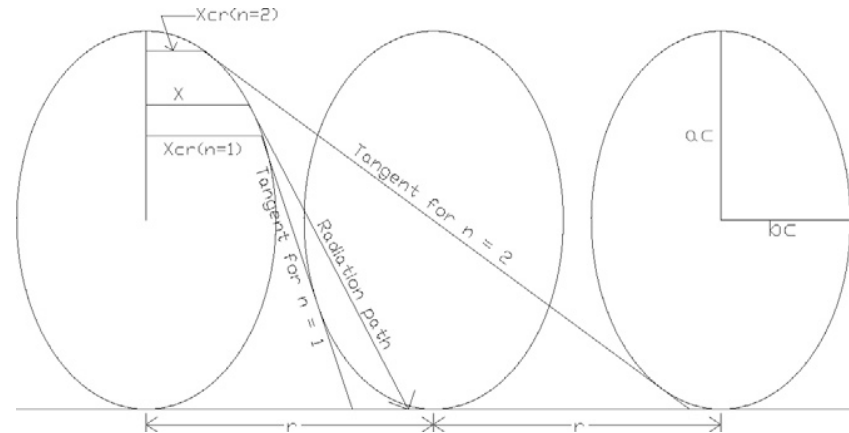

Fig. A2. Parameters used to compute $M_{R}$ (multiple row factor) for a radiation path through canopy rows modeled as continuous ellipses.
A radiation path tangent to the far left ellipse a distance $X$ from its center, where $X_{\mathrm{CR}}(2) \leq X \leq X_{\mathrm{CR}}(1)$, will pass through row $n=1$. In general, a radiation path will pass through row $n$ where $X_{\mathrm{CR}}(n+1) \leq X \leq X_{\mathrm{CR}}(n)$. If the radiation path refers to a solar beam, then $X$ becomes $X_{\mathrm{S}}$ and is given by Eq. [A6]; if the radiation path refers to a radiometer view angle, then $X$ becomes $X_{\mathrm{R}}$, which is computed by replacing $\theta_{\mathrm{SP}}$ with $\theta_{\mathrm{RP}}$ in Eq. [A6]. Then $M_{\mathrm{R}}$ is defined as:

$$
\begin{array}{cc}
M_{\mathrm{R}} \equiv n+\frac{X_{\mathrm{CR}}(n)-X}{X_{\mathrm{CR}}(n)-X_{\mathrm{CR}}(n+1)} & X_{\mathrm{CR}}(n+1) \leq X \leq X_{\mathrm{CR}}(n) \\
M_{\mathrm{R}} \equiv 1.0 & X \geq X_{\mathrm{CR}}(1)
\end{array}
$$

Beginning with $n=1, \mathrm{n}$ is incremented by 1 until $X>X_{\mathrm{CR}}(n)$.

\begin{tabular}{|c|c|}
\hline Symbol & Definition (units are shown in parentheses) \\
\hline$a_{C}$ & Vertical semiaxis of continuous ellipse that represents a canopy cross-section $(\mathrm{m})$ \\
\hline$A_{\mathrm{HI}, \mathrm{H} 2, \mathrm{H} 3, \mathrm{H} 4}$ & Areas within the radiometer footprint bound by chords in Fig. I $\left(\mathrm{m}^{2}\right)$ \\
\hline$A_{\mathrm{R}}$ & Area of the radiometer footprint $\left(\mathrm{m}^{2}\right)$ \\
\hline$a_{\mathrm{R}}$ & Vertical semiaxis of radiometer elliptical footprint $(\mathrm{m})$ \\
\hline$a_{\mathrm{R}, \mathrm{MAX}}$ & Maximum vertical semiaxis of a radiometer elliptical footprint, constrained by digital photograph in the present study $(\mathrm{m})$ \\
\hline$b_{C}$ & Horizontal semiaxis of continuous ellipse that represents a canopy cross-section $(m)$ \\
\hline$b_{C R}$ & Horizontal semiaxis of continuous ellipse that represents a canopy cross-section projected along the radiometer azimuth view angle $(\mathrm{m})$ \\
\hline$b_{\mathrm{R}}$ & Horizontal semiaxis of radiometer elliptical footprint $(\mathrm{m})$ \\
\hline$f_{C}^{\prime}$ & Area fraction of a solid canopy (i.e., impenetrable to light) appearing in the radiometer footprint (no units) \\
\hline$f_{\text {SOIL,SHD }}$ & Area fraction of shaded soil appearing in the radiometer footprint for a canopy penetrable to light (no units) \\
\hline$f_{\text {SOIL,SHD }}$ & Area fraction of shaded soil appearing in the radiometer footprint for a solid canopy (i.e., impenetrable to light) (no units) \\
\hline$f_{\text {SOIL,SUN }}$ & Area fraction of sunlit soil appearing in the radiometer footprint for a canopy penetrable to light (no units) \\
\hline$f_{\text {SOIL,SUN' }}$ & Area fraction of sunlit soil appearing in the radiometer footprint for a solid canopy (i.e., impenetrable to light) (no units) \\
\hline$f_{V E G, S H D}$ & Area fraction of shaded vegetation appearing in the radiometer footprint for a canopy penetrable to light (no units) \\
\hline$f_{\mathrm{VEG}, \mathrm{SUN}}$ & Area fraction of sunlit vegetation appearing in the radiometer footprint for a canopy penetrable to light (no units) \\
\hline $\mathrm{H}_{1}, \mathrm{H}_{2}, \mathrm{H}_{3}, \mathrm{H}_{4}$ & Distances of the chords from point B in Fig. I(m) \\
\hline$M_{\mathrm{R}}$ & Multiple row factor that accounts for a radiation path traversing across more than one canopy row (i.e., at greater zenith angles; no units) \\
\hline$N_{R}$ & Total number of rows used in computing $\mathrm{H}_{1}, \mathrm{H}_{2}, \mathrm{H}_{3}$, and $\mathrm{H}_{4}$ for multiple rows appearing in the radiometer footprint (no units) \\
\hline$O_{\mathrm{R}}$ & Horizontal distance from the radiometer to the near quadrant of its footprint (point B in Fig. I;m) \\
\hline$P_{\mathrm{L}}$ & Path length fraction of a radiation path through a canopy relative to nadir (no units) \\
\hline$P_{\mathrm{R}}$ & Horizontal, perpendicular distance from the radiometer to the row center $(\mathrm{m})$ \\
\hline$T_{\mathrm{R}}$ & $\begin{array}{l}\text { Distance from the footprint center, along the major axis, to a line tangent to the footprint forming angle } \Phi_{R} \text { with the major axis; } T_{R} \text { is used } \\
\text { in computing } N_{R}(m)\end{array}$ \\
\hline$V_{R}$ & Vertical distance of the radiometer from the ground $(\mathrm{m})$ \\
\hline$x, y, z$ & Coordinate distances from canopy ellipse origin (Fig.AI) to intersection of radiation path and ellipse boundary; used in computing $P_{\mathrm{L}}(\mathrm{m})$ \\
\hline$x_{C}$ & Horizontal distance from the canopy ellipse origin (Fig. I) to the radiometer along the radiometer azimuth view angle (m) \\
\hline$X_{C R}$ & Distance from canopy ellipse origin (Fig. A2) to a line tangent to adjacent canopy ellipses; $X_{C R}$ is used in computing $M_{R}(m)$ \\
\hline$X_{R}$ & $\begin{array}{l}\text { Horizontal distance from the canopy ellipse origin (Fig.A2) to the radiometer view path tangent to the canopy ellipse; } X_{R} \text { is used in } \\
\text { computing } M_{R}(m)\end{array}$ \\
\hline$X_{S}$ & Horizontal distance from the canopy ellipse origin (Fig. I) to a solar beam tangent to the canopy ellipse (m) \\
\hline$x_{\mathrm{T}}$ & Horizontal distance from the canopy ellipse origin (Fig. I) to the radiometer footprint tangent along the radiometer view azimuth angle $(\mathrm{m})$ \\
\hline$y_{C}$ & Vertical distance from the canopy ellipse origin (Fig. I) to the radiometer $(\mathrm{m})$ \\
\hline$Y_{S}$ & Vertical distance from the canopy ellipse origin (Fig. I) to the tangent of the solar beam (m) \\
\hline$y_{\mathrm{T}}$ & Vertical distance from the canopy ellipse origin (Fig. I) to the radiometer footprint tangent (m) \\
\hline$\theta_{1}, \theta_{2}$ & Zenith angles formed by the near and far, respectively, radiometer field-of-view boundaries of the canopy in Fig. I (rad) \\
\hline$\theta_{\mathrm{P}}$ & Projected zenith angle along the radiation path relative to the row orientation (rad) \\
\hline$\theta_{\mathrm{RP}}$ & Projected radiometer zenith angle along the radiation path relative to the row orientation ( $\mathrm{rad}$ ) \\
\hline$\theta_{S P}$ & Projected solar zenith angle along the radiation path relative to the canopy ellipse (rad) \\
\hline$x_{b}$ & Extinction coefficient for direct beam radiation (no units) \\
\hline$\tau_{b}\left(\theta_{R}\right)$ & Transmittance of shortwave or longwave radiation for a radiometer viewing the canopy at zenith angle $\theta_{R}$ (no units) \\
\hline$\tau_{\mathrm{b}}\left(\theta_{\mathrm{S}}\right)$ & Transmittance of beam solar radiation through a canopy at solar zenith angle $\theta_{S}$ (no units) \\
\hline
\end{tabular}

\section{Symbols Specific to the Continuous Ellipse Model.}




\section{REFERENCES}

Allen, L.H. 1974. Model of light penetration into a wide-row crop. Agron. J. 66:41-47.

Anderson, M.C., C.M.U. Neale, F. Li, J.M. Norman, W.P. Kustas, H. Jayanthi, and J. Chavez. 2004. Upscaling ground observations of vegetation water content, canopy height, and leaf area index during SMEX02 using aircraft and Landsat imagery. Remote Sens. Environ. 92:447-464.

Anderson, M.C., J.M. Norman, W.P. Kustas, F. Li, J.H. Prueger, and J.R. Mecikalski. 2005. Effects of vegetation clumping on two-source model estimates of surface energy fluxes from an agricultural landscape during SMACEX. J. Hydrometeorol. 6:892-909.

Arkin, G.F., J.T. Richie, and S.J. Maas. 1978. A model for calculating light interception by a grain sorghum canopy. Trans. ASAE 21:303-308.

Baker, J.M., J.M. Norman, and A. Kano. 2001. A new approach to infrared thermometry. Agric. For. Meteorol. 108:281-292.

Bugbee, B., M. Droter, O. Monje, and B. Tanner. 1998. Evaluation and modification of commercial infrared transducers for leaf temperature measurement. Adv. Space Res. 22:1425-1434.

Campbell, G.S., and J.M. Norman. 1998. An introduction to environmental biophysics. 2nd ed. Springer-Verlag, New York.

Chen, J.M., and J. Cihlar. 1995. Quantifying the effect of canopy architecture on optical measurements of leaf area index using two gap size analysis methods. IEEE Trans. Geosci. Rem. Sens. 33:777-787.

Colaizzi, P.D., E.M. Barnes, T.R. Clarke, C.Y. Choi, and P.M. Waller. 2003a. Estimating soil moisture under low frequency irrigation. J. Irrig. Drain. Eng. 129:27-35.

Colaizzi, P.D., E.M. Barnes, T.R. Clarke, C.Y. Choi, P.M. Waller, J. Haberland, and M. Kostrzewski. 2003b. Water stress detection under high frequency sprinkler irrigation with water deficit index. J. Irrig. Drain. Eng. 129:36-43.

Colaizzi, P.D., P.H. Gowda, T.H. Marek, and D.O. Porter. 2009. Irrigation in the Texas High Plains: A brief history and potential reductions in demand. Irrig Drain. 58:257-274 doi:10.1002/ird.418.

El-Shikha, D.M., P.M. Waller, T.R. Clarke, D.J. Hunsaker, and E.M. Barnes. 2007. Ground-based remote sensing of water and nitrogen status of broccoli. Agric. Water Manage. 92:183-193.

El-Shikha, D.M., E.M. Barnes, T.R. Clarke, D.J. Hunsaker, J.A. Haberland, P.J. Pinter, Jr., P.M. Waller, and T.L. Thompson. 2008. Remote sensing of cotton nitrogen status using the Canopy Chlorophyll Content Index (CCCI). Trans. ASABE 51:73-82.

Fitzgerald, G.J., P.J. Pinter, Jr., D.J. Hunsaker, and T.R. Clarke. 2005. Multiple shadow fractions in spectral mixture analysis of a cotton canopy. Remote Sens. Environ. 97:526-539.

Gijzen, H., and J. Goudriaan. 1989. A flexible and explanatory model of light distribution and photosynthesis in row crops. Agric. For. Meteorol. 48:1-20.

Haberland, J.A., P.D. Colaizzi, M.A. Kostrzewski, P.M. Waller, C.Y. Choi, F.E. Eaton, E.M. Barnes, and T.R. Clarke. 2010. AGIIS, Agricultural irrigation imaging system. Appl. Eng. Agric. (in press).

Howell, T.A., A. Yazar, A.D. Schneider, D.A. Dusek, and K.S. Copeland. 1995a. Yield and water use efficiency of corn in response to LEPA irrigation. Trans. ASAE 38:1737-1747.

Howell, T.A.,J.L.Steiner, A.D. Schneider, and S.R. Evett. 1995b. Evapotranspiration of irrigated winter wheat: Southern High Plains. Trans. ASABE 38:745-759.
Howell, T.A., J.L. Steiner, A.D. Schneider, S.R. Evett, and J.A. Tolk. 1997. Seasonal and maximum daily evapotranspiration of irrigated winter wheat, sorghum, and corn: Southern High Plains. Trans. ASABE 40:623-634.

Howell, T.A., S.R. Evett, J.A. Tolk, and A.D. Schneider. 2004. Evapotranspiration of full-, deficit-irrigation, and dryland cotton on the Northern Texas High Plains. J. Irrig. Drain. Eng. 130:277-285.

Hunsaker, D.J., D.M. El-Shikha, T.R. Clarke, A.N. French, and K.R. Thorp. 2009. Using ESAP software for predicting the spatial distributions of NDVI and transpiration in cotton. Agric. Water Manage. 96:1293-1304.

Jackson, R.D. 1984. Remote sensing of vegetation characteristics for farm management. Proc. SPIE 475:81-96.

Jackson, R.D., R.J. Reginato, P.J. Pinter, Jr., and S.B. Idso. 1979. Plant canopy information extraction from composite scene reflectance of row crops. Appl. Opt. 18:3775-3782.

Kimes, D.S. 1983. Remote sensing of row crop structure and component temperatures using directional radiometric temperatures and inversion techniques. Remote Sens. Environ. 13:33-55.

Kostrzewski, M., P. Waller, P. Guertin, J. Haberland, P.D. Colaizzi, E. Barnes, T. Thompson, T. Clarke, E. Riley, and C. Choi. 2003. Ground-based remote sensing of water and nitrogen stress. Trans. ASABE 46:29-38.

Kustas, W.P., and J.M. Norman. 1999. Evaluation of soil and vegetation heat flux predictions using a simple two-source model with radiometric temperatures for partial canopy cover. Agric. For. Meteorol. 94:13-29.

Legates, D.R., and G.J. McCabe, Jr. 1999. Evaluating the use of "goodness-offit" measures in hydrologic and hydroclimatic model validation. Water Resour. Res. 35:233-241.

Li, F., W.P. Kustas, J.H. Prueger, C.M.U. Neale, and J.T. Jackson. 2005. Utility of remote sensing-based two-source energy balance model under lowand high-vegetation cover conditions. J. Hydrometeorol. 6:878-891.

Mann, J.E., G.L. Curry, D.W. DeMichele, and D.N. Baker. 1980. Light penetration in a row-crop with random plant spacing. Agron. J. 72:131-142.

Moran, M.S. 1994. Irrigation management in Arizona using satellites and airplanes. Irrig. Sci. 15:35-44.

Nilson, T. 1971. A theoretical analysis of the frequency of gaps in plant stands. Agric. Meteorol. 8:25-38.

Norman, J.M., and J.M. Welles. 1983. Radiative transfer in an array of canopies. Agron. J. 75:481-488.

Peters, R.T., and S.R. Evett. 2007. Spatial and temporal analysis of crop stress using multiple canopy temperature maps created with an array of centerpivot-mounted infrared thermometers. Trans. ASABE 50:919-927.

Peters, R.T., and S.R. Evett. 2008. Automation of a center pivot using the temperature-time-threshold method of irrigation scheduling. J. Irrig. Drain. Eng. 134:286-291.

Sadler, E.J., C.R. Camp, D.E. Evans, and J.A. Millen. 2002. Corn canopy temperatures measured with a moving infrared thermometer array. Trans. ASAE 45:581-591.

USDA-NRCS. 2009. Web Soil Survey, Soil Survey TX375, Potter County, Texas. Available at http://websoilsurvey.nrcs.usda.gov (accessed 22 June 2009; verified 18 Feb. 2010). USDA-NRCS, Washington, DC.

Wanjura, D.F., D.R. Upchurch, and J.R. Mahan. 1995. Control of irrigation scheduling using time-temperature thresholds. Trans. ASAE 38:403-409.

Zhan, X., W.P. Kustas, and K.S. Humes. 1996. An intercomparison study on models of sensible heat flux over partial canopy surfaces with remotely sensed surface temperature. Remote Sens. Environ. 58:242-256. 